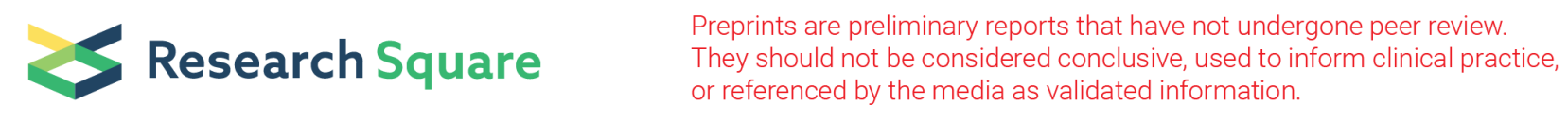

\title{
Rational Metabolic Engineering of Escherichia Coli for High-yield L-serine Production
}

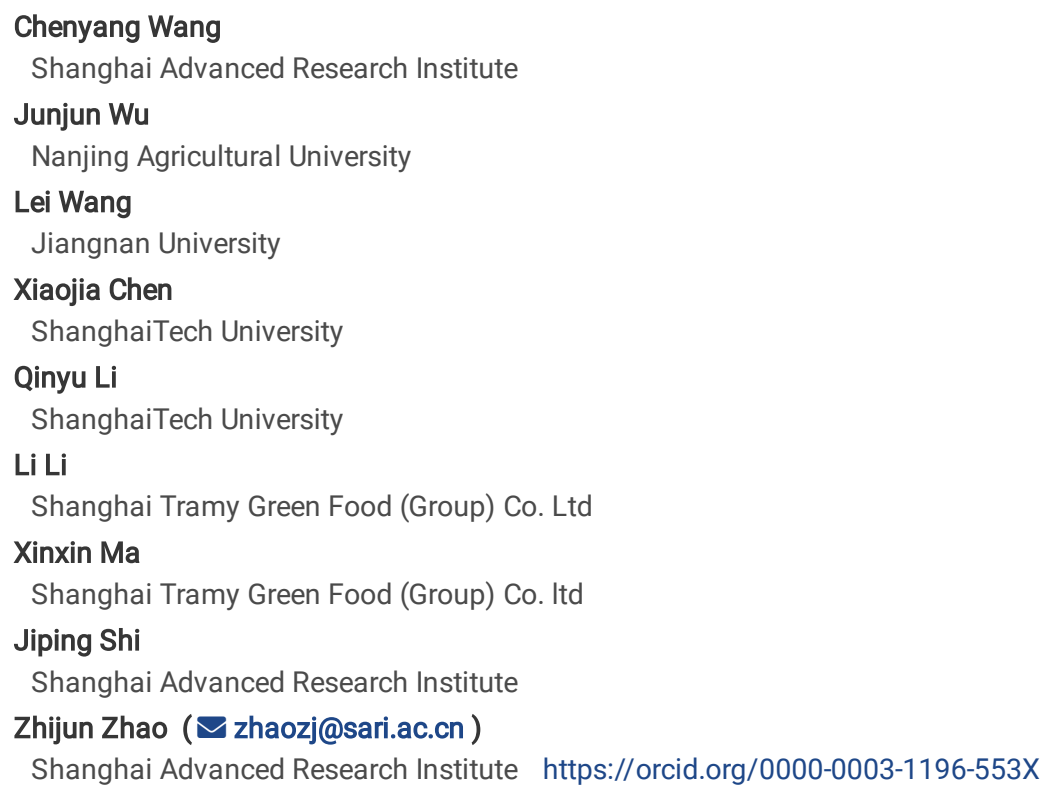

\section{Research}

Keywords: L-serine, E. coli, Metabolic Engineering, Fermentation

Posted Date: November 17th, 2020

DOI: https://doi.org/10.21203/rs.3.rs-105404/v1

License: (a) (1) This work is licensed under a Creative Commons Attribution 4.0 International License. Read Full License 


\section{Abstract}

Background: L-serine is widely used in the food, cosmetic and pharmaceutical industries, and direct fermentation of L-serine from glucose is an attractive technique. However, L-serine producers have historically been developed via classical random mutagenesis due to the complicated metabolic network and regulatory mechanism of $\mathrm{L}$-serine production, leading to un-optimal productivity and yield of L-serine and thus limiting its large-scale industrial production.

Result: In this study, a high-yield and high-productivity Escherichia coli strain was constructed by a defined genetic modification methodology for L-serine production. First, L-serine-mediated feedback inhibition was removed and L-serine biosynthetic pathway genes ( $\operatorname{ser} A^{f r}$, serC and $\operatorname{ser} B$ ) associated with phosphoglycerate kinase ( $p g k$ ) were overexpressed. Secondly, L-serine conversion pathway was further examined by introducing a glyA mutation (K229G) and deleting other degrading enzymes based on deletion of initial sdaA. Finally, the L-serine transport system was rationally engineered to reduce the uptake and accelerate the export of L-serine. The optimally engineered strain produced $35 \mathrm{~g} / \mathrm{L} \mathrm{L}$-serine with a productivity of $0.98 \mathrm{~g} / \mathrm{L} / \mathrm{h}$ and yield of 0.42 $\mathrm{g} / \mathrm{g}$ glucose in a 5-L fermenter, the highest productivity and yield of L-serine from glucose reported to date. Transcriptome and intermediate metabolite were analyzed to further understand the regulatory mechanism of L-serine production.

Conclusion: These results demonstrated that combined metabolic and bioprocess engineering strategies can improve L-serine productivity and yield, thus providing basic principles for rationally designing of high-yield production strains and paving the way for towards a simple and economical process for industrial L-serine production.

\section{Background}

L-serine(L-Ser) is a vital amino acid in metabolism in humans and other animals and is widely used in the food, pharmaceutical and cosmetic industries[1]. Additionally, L-Ser has been identified as one of the top 30 most interesting biochemical building block. Currently, L-Ser production relies on enzymatic or direct fermentation[2, 3], and the global L-Ser production capacity (350 tons per year) is well below the expected market demand (3000 tons per year)[4]. Therefore, it is necessary to develop a more effective L-Ser production method. Furthermore, demand exists for developing a direct fermentation approach that can be implemented with low-cost substrates and will can simplify operational purification procedures and reduce pollution, as enzymatic conversion always utilizes the expensive precursors glycine and methanol[5].

L-Ser production by microbial fermentation has been extensively studied in Corynebacterium glutamicum. In 2007, Petra Peters-Wendisch et al. engineered a $C$. glutamicum strain with an industrial production capacity $36 \mathrm{~g} / \mathrm{L}$ L-Ser[6-8]. The strain was constructed by overexpressing L-Ser pathway genes, deleting the L-Ser dehydratase $s d a A$, and reducing the expression of serine hydroxymethyltransferase (SHMT) encoded by gly $A$ and was cultured with an external folate supply[6-8]. Replacement of folate with corn steep liquor led to the production of an L-Ser titer of $43 \mathrm{~g} / \mathrm{L}$ in $96 \mathrm{~h}$ by another $C$. glutamicum strain with random mutation and minimization of by-product synthesis[9]. However, as a host, Escherichia coli has attracted attention due to its well-characterized genetic background, amenability to genetic manipulation, and faster growth rate, higher fermentation intensity and better utilization rate of glucose in direct fermentation[10]. More importantly, L-Ser can be produced from glucose by fermentation with a higher theoretical yield (approximately $1.34 \mathrm{~g} / \mathrm{g}$ glucose) in E. coli than in C. glutamicum $(1.16 \mathrm{~g} / \mathrm{g})[11]$.

Recently, Hemanshu Mundhada et al. developed a strain of $E$. coli with a production capacity of $11.7 \mathrm{~g} / \mathrm{L} \mathrm{L}-\mathrm{Ser}$ via ultraviolet radiation on a $1 \mathrm{~L}$ scale[1]. Then, this group increased the production capacity to $37 \mathrm{~g} / \mathrm{L}$ by adaptive laboratory evolution[12]. Subsequently, translation initiation optimization led to the production of an L-Ser titer of $50 \mathrm{~g} / \mathrm{L}$ with a yield of $0.36 \mathrm{~g} / \mathrm{g}$ from glucose in $60 \mathrm{~h}$ by strain ALE- 5 via evolution engineering this L-Ser production capacity is the highest of any strains to date[13]. However, the application of many random mutagenesis evens makes the description of efficient L-Ser synthesis mechanisms difficult. Furthermore, previous studies have shown that repeated random mutation often leads to unknown mutations at some locations in the genome together with targeted mutagenesis[14]. The impact of these unknown mutations is difficult to determine. Moreover, whether the unknown mutations affect universally industrialized fermentation. All these factors limit the application of these strains in industrial production.

In this study, an L-Ser-producing strain was constructed from E. coli W3110 by introducing a series of defined genetic manipulations (Fig. 1). A basic production strain was constructed by strengthening the L-Ser biosynthesis. Then L-Ser degradation and conversion pathways were optimized. Higher production was further achieved by engineering the L-serine transporter system. The rational design strategies described here significantly improved Lserine productivity and yield in fed-batch fermentation.

\section{Results And Discussion}

\subsection{Construction of the L-serine production strain from E. coli W3110}

As a prerequisite for L-Ser production, the activity of the branch pathway leading to L-Ser biosynthesis, which involves serA, serC and serB, was enhanced. PGDH, encoded by serA, catalyzes the initial reaction in L-Ser biosynthesis and the catalytic activity of PGDH can be regulated by feedback inhibition by LSer in E. coli[23]. The feedback inhibition was overcome by mutation of two residues (344 and 346) to alanine, as previously described, which would remove the hydrogen bonds between L-Ser and the regulatory binding domain. This led to the mutated gene named ser $A^{f i}$ [24]. The feedback resistance of the enzyme PGDH, encoded by $s e r A^{f r}$, was investigated by overexpressing these genes in BL21(DE3) via the pT7-7 vector. The activity of ser $A^{f r}$ could was sustained at $95 \%$ with $80 \mathrm{mmol} / \mathrm{L}$ L-Ser, whereas the activity of the wild-type enzyme remained at only $10 \%$ (Fig. $2 A)$. Then, ser $A^{\text {fr }}$, serC, and serB were overexpressed in the low copy number pSC vector containing the PR or PL promoter with resulting in SP-01, SP-02 and SP-03 (Fig. 2B).

Page 2/18 
To produce L-Ser, the sdaA gene encoding the L-Ser-specific dehydratase was first deleted from E. coli W3110 to construct the SSW-01 strain. Subsequent deletion of glyA, encoding SHMT, which converts L-Ser to glycine, resulted in the double knockout SSW-02 strain. To evaluate the L-Ser production capacity, the resulting plasmids SP-01 (SP-ser $\left.A^{f \prime}\right)$, SP-02 (SP-ser $A^{f r} C$ ) and SP-05(SP-ser $A^{f r} B C$ ) were transformed into SSW-02. As shown in Fig. 2C, strain SSW-02/SP-01 was grown in M9-yeast medium supplemented with $50 \mathrm{mmol}$ glucose, and the final concentration of L-Ser was $155 \mathrm{mg} / \mathrm{L}$ after $15 \mathrm{~h}$ in a shake flask. An L-Ser concentration of $220 \mathrm{mg} / \mathrm{L}, 42 \%$ higher than that obtained by culturing SSW-02/SP-01, was obtained by culturing SSW-02/SP-02. SSW-02/SP-05 attained the highest L-Ser concentration, $270 \mathrm{mg} / \mathrm{L}$, which exhibited 1.74-fold increase compared to only overexpressing ser $A^{f r}$. The L-Ser accumulation profile shown in Fig. 2C, indicates that the production of L-Ser increased as more biosynthetic genes were overexpressed.

Furthermore, previous studies have shown that only $15 \%$ of the carbon assimilated from glucose is directed into the L-Ser biosynthetic pathway in $E$.

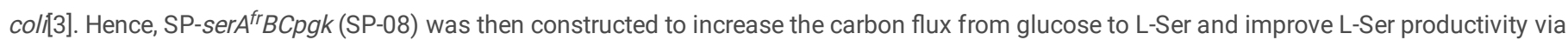
amplification of phosphoglycerate kinase encoded, by pgk (Fig. 2B). Flask culture of the recombinant SSW-02/SP-08 strain produced a final L-Ser concentration of $311 \mathrm{mg} / \mathrm{L}, 15 \%$ higher than that obtained by culturing SSW-02/SP-05 (Fig. 2C). Thus, overexpression of $p g k$ effectively improved the LSer production capacity of the strain. To further examine L-Ser production of SSW-02/SP-08, fed-batch fermentation was performed in a 5-L fermenter. The highest L-Ser concentration, $17.7 \mathrm{~g} / \mathrm{L}$, was observed at $32 \mathrm{~h}$ with a yield of $24 \%$ from glucose (Fig. 2D).

\subsection{Influence of mutations in glyA on L-serine production and cell growth}

A previous study showed that attenuation of glyA transcription resulted in increased L-Ser accumulation, a decrease in the purine pool, poor growth and cell elongation (Fig S1, Additional file 1)[25, 26]. The same phenomenon was observed in this study; SSW-02 cells were elongated and exhibited unstable growth at the early stage of fermentation. We reprogrammed the predominant one-carbon source metabolism with suppressed SHMT activity to increase the stability of the strains. A series of error-prone PCRs were employed to construc a glyA mutation library[27]. Different reductions in SHMT activity were obtained and examined by transforming the recombinant plasmids harboring $g l y A^{m u t}$ into BL21(DE3). As shown in Table 4, SHMT encoded by gly $A^{\text {mut }}$ (K229G) showed an activity of $0.13 \mathrm{U}$, which decreased by $41 \%$ compared to wild type. The mutant K229G was modeled by SWISSMODEL based on the wild type SHMT (PDB ID, 1DFO). As shown in Fig. 3A, close view of the SHMT K229G mutant compared with the wild type SHMT complexed with cofactor LPL (pyridoxal 5'-phosphate) and THFA (PDB ID, 1DFO). The side chain of the K229, which involved the degradation of L-Ser, was removed to obtain the mutant K229G [28]. Sequentially, the glyA gene in SSW-01 was replaced with the appropriate gly ${ }^{\text {mut }}$ (K229G) via CRISPR/Cas9 to generate SSW-03 $\left(\triangle s d a A g l y A^{m u t}\right)$. Then, the L-Ser biosynthesis plasmid SP-08 was transformed into SSW-03, and cell growth and L-Ser production were evaluated. As shown in Fig. 3B, gly $A^{m u t}$ introduction resulted in a $24 \%$ increase in biomass, and cultured cells maintained stable growth throughout repeated experiments. SSW-03/SP-08 produced $21.6 \mathrm{~g} / \mathrm{L}$ of L-Ser, an increase of 22\% compared to SSW-02/SP-08.

\subsection{Influence of $s d a B$, ilvA, $t d c B$ and $t d c G$ deletion on L-serine production}

The L-Ser production capacity of $E$. coli was significantly increased by overexpression of $\operatorname{ser} A^{f r}$, serB, $\operatorname{ser} C$ and $p g k$ via knockout of the $s d a A$ and mutation of glyA. The four genes other than $s d a A$ and $g l y A$, i.e., $s d a B, i l v A, t d c B$ and $t d c G$, have been reported to transform L-Ser to pyruvate in $E$. coli [29, 30]. However, previous studies focused mainly on decreasing the degradation of L-Ser by deleting all of these genes simultaneously, and few studies have systematically investigated the individual contribution of these degradation genes to L-Ser production. To prevent the degradation and improve the production of L-Ser, $s d a B, i l v A, t d c B$ and $t d c G$ were knocked out individually in the SSW-03 background to generate strains SSW-05, SSW-06, SSW-07 and SSW-08 (Fig. 4A). The plasmid SP-08 was transformed into these mutant strains to produce L-Ser. As shown in Fig. 4B, strain SSW-05/SP-08, which had $s d a B$ deletion, showed the highest L-Ser production of $26.5 \mathrm{~g} / \mathrm{L}$, an increase of $23 \%$ compared to SSW-03/SP-08. This result was expected, because the SSW-05/SP-08 biomass was also increased by $16 \%$, and SSW-05/SP-08 showed an L-Ser productivity of nearly $0.87 \mathrm{~g} / \mathrm{L} / \mathrm{h}$ at $28 \mathrm{~h}$. While the ilvA gene was knocked out, the growth of the strains was severely inhibited, and production could not be induced during fermentation of SSW-07/SP-08 (Fig. 4C). The growth restriction of SSW-06/SP-08 may be due to disruption of branched chain amino acid synthesis by deletion of $i / v A[31]$. Regarding the $t d c B$ gene, the marginal difference in the L-Ser titer and biomass between the SSW-03/SP-08 and SSW-07/SP-08 strains indicated that deletion of $t d c B$ is insufficient to improve L-Ser production (Fig. 4D). However, fermentation of deletion of $t d c G$ exhibited unexpected results. This $t d c G$ gene knockout strain, SSW-08/SP-08, showed a same biomass and 42\% lower L-Ser production than the SSW-03/SP-08 (OD $600 \sim 36,21.6 \mathrm{~g} / \mathrm{L})$ (Fig. 4B and Fig. 4E). The complex phenomenon associated with SSW-09/SP-08 may be caused by regulation of the expression of the interrupted operon $t d C A B C D E F G$ by deletion of $t d c G$. These results suggested that only deletion of $s d a B$ improved L-Ser production, increasing the L-Ser titer by $23 \%$; thus, SSW- 05 with only deletion of $s d a B$ was selected for the following experiment, which would avoid severely affected in cell growth by knockout all L-Ser dehydratases.

\subsection{Effect of engineering L-serine transport system on strain productivity}

Moreover, engineering amino acid transport system is also important to further improving strain productivity by blocking reuptake of amino acid and reducing futile cycles [32, 33]. In E. coli, four genes, sstT[34], $c y c A[35], s d a C[36]$ and $t d c C[37]$, have been reported to be involved in L-Ser uptake. Notably, $s d a C$ is the only gene described as a highly specific serine transporter, and deletion of $s d a C$ was found to improve L-Ser production in our recent studies[38]. Thus, the highly specific L-Ser uptake gene sdaC was deleted from SSW-05 to reduce the unwanted futile cycles caused by L-Ser reuptake; this deletion resulted in strain SSW-10. As shown in Fig. 5A, the SSW-10/SP-08 produced $30 \mathrm{~g} / \mathrm{L} \mathrm{L}-\mathrm{Ser}$ with a yield of $0.37 \mathrm{~g} / \mathrm{g}$ from glucose, $16 \%$ higher than that of SSW-05/SP-08. In addition, the final L-Ser productivity of SSW-10/SP-08 was approximately $0.84 \mathrm{~g} / \mathrm{L} / \mathrm{h}$, which was almost $1.15-$ fold that of SSW-05/SP-08.

Efflux pump is an important component of amino acid transport system and it is known to increase strain tolerance by accelerating the export of amino acid from cells. However, no research to date has reported well-characterized L-Ser exporters in E. coli. ThrE has been identified as an L-Ser/L-threonine

Page $3 / 18$ 
exporter in C. glutamicum [39]. And thrE family identified as amino acid exporters in select bacteria, archaea and eukaryotes, but no homologues were found in E.coli[40]. Here, heterologous expression of thrE was performed to verify if it works in E.coli. Thus, thrE was cloned into the constructed expression vector SP-08 adjacent to the PR promoter, resulting in the plasmid SP-09 (Fig. 5B). This recombinant plasmid was then transformed into SSW10. Figure $5 B$ shows the fermentation process of SSW-10/SP-09. Overexpression of thrE resulted in a $9 \%$ decrease in the final $O D_{600}$ value and an $16 \%$ increase in L-Ser production compared to those of SSW-10/SP-08. Although the L-Ser production by the final strain SSW-10/SP-09 (35.1 g/L) was lower than L-Ser production by the strains constructed by Maja Rennig (50 g/L), the yield (42\%) of L-Ser from glucose of strain SSW- $10 / \mathrm{SP}-09$ was higher than that of the strains constructed by Maja Rennig (36\%)[13]. Moreover, strain SSW-10/SP-09 exhibited highest productivity and yield of L-Ser from glucose observed to date.

\subsection{Transcriptomic analysis of of E. coli W3110 and SSW-10/SP-09}

To investigate the effect of L-Ser fermentation on intracellular metabolism, transcriptomic analyses of E. coli W3110 and SSW-10/SP-09 were performed in the exponential phase. A total of 1679 transcripts were found to be significantly different under two criteria ( $p$-value $<0.05$ and fold change $>2.0$ ). Transcription levels in central carbon metabolism, including glycolysis, tricarboxylic acid(TCA) cycle and amino acid pathways related L-Ser synthesis, were compared.

Expression of the genes related to most reactions in the glycolysis such as pgi, fabAB, tpiA, eno, and pyk was downregulated in SSW-10/SP-09, while that of $p g k$, encoding phosphoglycerate kinase, was upregulated due to its expression in plasmid SP-09 (Fig. 6A). In the TCA cycle, expression of most genes were also downregulated in SSW-10/SP-09 (Fig. 6B). As a main machinery for adenosine triphosphate(ATP) synthesis, TCA cycle could produce 12.5 ATP molecules per pyruvic acid (PYR) molecule with important intermediates such as oxaloacetate(OAA) and acetyl-CoA(AcCoA)[41]. Downregulation of TCA cycle might cause inferior growth with less energy supply. However, the mqo gene encoding malate dehydrogenase that convert malate with quinone to oxaloacetate and reduced quinone was upregulated. Reduced quinone could significantly decrease global DNA methylation level cells, and cause acute oxidative damage[42]. Reduced quinone rise in SSW-10/SP-09 may be another reason for biomass decrease. In this study, the OD 600 of SSW- $10 /$ SP- $_{0} 9$ was 24 , a decrease of $35 \%$ compared to that of E. coli W3110 $\left(\mathrm{OD}_{600}=37\right)$. Gene $s d h C$, encoding succinate dehydrogenase (ubiquinone) cytochrome b560 subunit, was related to in oxygen availability and upregulated in SSW-10/SP-09[43].

Next, we analyzed changes in the expression of genes related to L-Ser production in SSW-10/SP-09 (Fig. 6C). The expression levels of serA, serC and serB increased in varying degrees. Expression of the gene glnA related to conversion from L-glutamic acid (L-Glu) to L-glutamine(L-Gln), which provided $\mathrm{NH} 4^{+}$ for L-Ser biosynthesis, was upregulated. It caused damping reaction in L-Glu, L-Gln and 2-oxoglutarate(2-OXO) such as gltB and gltD. Expression of the $d s d A$ encoding D-Ser ammonia-lyase was upregulated. However, expression of $c y s E K O$, Itae and trpAB involved in L-cysteine(L-Cys) and L-tryptophan(LTrp) biosynthesis were not change. Likewise, SSW-10/SP-09 showed downregulation of glycine cleavage(Gcv) system genes such as $g c v T$, gcv $P$ and gcvH due to less intracellular glycine(Gly) (Fig. 6D). It could result in a decreased amount of one-carbon units and poor growth [44]. However, metF, encoding 5,10-CH2-THF reductase, involved in one-carbon metabolism drastically increased, which could compensate for one-carbon unit [45]. Expression of the betB encoding the enzymes that converts betaine aldehyde to betaine was upregulated. Betaine could regulate intracellular osmotic pressure and provide methyl [46]. With supplement betaine, production of L-threonine, cobalamin and L-lactate were increased[47]. Expression of genes related to metabolism of L-threonine(L-Thr), a downstream amino acid of L-Ser, was analyzed (Fig. 6E). The expression levels of ilvA, which was involved in both LThr and L-Ser dehydration, was decreased.

In addition to the above genes, there were still large number of differentially expressed genes. Among the upregulated genes in "pyrimidine metabolism" of SSW-10/SP-09, five gene sets rutA(expression ratio $2^{5.37}$ ), rutB(expression ratio $2^{4.55}$ ), rutC(expression ratio $2^{4.09}$ ), rutD(expression ratio $2^{2.30}$ ) and rutE(expression ratio $2^{2.44}$ ). Rut pathway may be proposed to enhance the rate of hydrolysis of aminoacrylate, a toxic side product of L-Ser degradation[48, 49]. Among the downregulated genes, genes in the category "Galactose metabolism" were enriched in SSW-10/SP-09. This category includes gat $Z$ (expression ratio $2^{-3.89}$ ), gat $A\left(\right.$ expression ratio $2^{-6.60}$ ), gat $B\left(\right.$ expression ratio $2^{-8.45}$ ), gatC(expression ratio $2^{-6.55}$ ), gat $D\left(\right.$ expression ratio $2^{-}$ ${ }^{6.87}$ ) and gatR'(expression ratio $2^{-3.52}$ ). Genes gatZABCDR'related to dihydroxyacetone phosphate synthesis from galactitol and galactosamine were highly involved in biofilms and downregulation of the operon may have connection to cell density decrease [50].

\subsection{Intermediate metabolite analysis of of E. coli W3110 and SSW-10/SP-09}

As shown in Fig. 7A, a set of 17 intracellular metabolites, including glycolytic intermediates, intermediate metabolite in TCA cycle and amino acid related L-Ser, were measured. A score plot of the PCA model using 17 intracellular metabolites showed the discrimination of metabolite profiles depending on different strains (Fig. 7B). In the PCA model, the intracellular metabolite profiles of E. coli W3110 and SSW-10/SP-09 were clearly discriminated. Along the axis of PC1 of the score plot, the metabolite profiles of E. coli W3110 were located on the positive side, while the metabolite profiles of SSW-10/SP-09 were located on the negative side. Intracellular glucose-6-phosphate (G6P) concentration of SSW-02/SP-08 increased. It may be caused by downregulated of most downstream genes such as pgi, fabAB and eno in glycolysis (Fig. 8A and Fig. 9A). Intracellular PYR concentration decreased due to weak glycolysis and efficient carbon flux on L-Ser. In the TCA cycle, 2-OXO concentration and malic acid (MAL) concentration showed no significant changes between SSW-10/SP-09 and E. coli W3110. Intracellular L-Ser concentration was $472.5 \mu \mathrm{g} / \mathrm{L} / \mathrm{g}_{(\mathrm{DCW})}$, which was 32 -fold of control. Consumption of L-GIn, pitched into the second step of L-Ser biosynthesis, caused damage of its precursor L-Glu. High intracellular L-Thr concentration was in favor of maintaining L-Gly concentration $[12,51]$. It also was the reason for the lessened concentration of L-valine (L-Val), L-leucine (L-Leu) and L-isoleucine (L-lle). Higher intracellular L-Thr concentration also caused downregulation of thrABC (encoding homoserine dehydrogenase I, homoserine kinase, and threonine synthetase), which was consistent with the result showed in Fig. 8C, due to its feedback inhibition [21]. Intracellular L-phenylalanine (L-Phe) concentration 
of SSW-10/SP-09 increased 182\% when compared to it of E. coli W3110. While there was no distinct relationship reported between L-Phe and L-Ser production to date.

\section{Conclusions}

In this study, a systematic investigation was performed in E. coli to construct an L-serine-producing strain with defined genetic modification. Pure rational metabolic engineering of L-serine-producing strain would provide clearly information for the further improvement, which are difficult to be applied on the random mutagenesis strains because of unknown mutations in their genomes. The key genes ( $\operatorname{ser} A^{f r}$, serC, serB and $p g k$ ) for L-serine biosynthesis were overexpressed. The transformation pathways were optimized by introducing a glyA mutation (K229G) and deleting $s d a A$ and $s d a B$. Furthermore, L-Ser uptake gene $s d a C$ was deleted and L-serine/L-threonine exporter ThrE was overexpressed. L-serine production of $35 \mathrm{~g} / \mathrm{L}$ with the highest productivity of $0.98 \mathrm{~g} / \mathrm{L} / \mathrm{h}$ and yield of $0.42 \mathrm{~g} / \mathrm{g}$ glucose was finally achieved. The analysis of transcriptome and intermediate metabolites was performed to further understand the regulatory mechanisms of L-serine production. The fermentation-based process described herein provides an important step towards the industrial production of L-serine directly from glucose. Moreover, further strain development can be achieved through genetic optimization of SSW-10/SP09 with completely defined genomic traits.

\section{Materials And Methods}

\subsection{Strains, media and materials}

Wild-type E. coli W3110 was used as the parent strain for serial engineering of L-Ser production. E. coli 5 a was used for cloning and propagation of plasmids. E. coli BL21(DE3) was used for enzyme assays. Further strains constructed in this study are shown in Table 1. For strain construction, cultures were grown at $30^{\circ} \mathrm{C}$ or $37^{\circ} \mathrm{C} \mathrm{C}$ in Luria-Bertani medium (LB; $10 \mathrm{~g} / \mathrm{L}$ tryptone, $10 \mathrm{~g} / \mathrm{L} \mathrm{NaCl}, 5 \mathrm{~g} / \mathrm{L}$ yeast extract) and supplemented with antibiotics as appropriate.

For L-Ser production, minimal M9 medium $\left(6.8 \mathrm{~g} / \mathrm{L} \mathrm{Na}_{2} \mathrm{HPO}_{4}, 3 \mathrm{~g} / \mathrm{L} \mathrm{KH} 2 \mathrm{PO}_{4}, 0.5 \mathrm{~g} / \mathrm{L} \mathrm{NaCl}, 1 \mathrm{~g} / \mathrm{L} \mathrm{NH}_{4} \mathrm{Cl}, 0.015 \mathrm{~g} / \mathrm{L} \mathrm{CaCl} \cdot 2 \mathrm{H}_{2} \mathrm{O}, 0.49 \mathrm{~g} / \mathrm{L} \mathrm{MgSO} \cdot 7 \mathrm{H}_{2} \mathrm{O}\right.$ and $2.8 \times 10^{-4} \mathrm{~g} / \mathrm{L} \mathrm{MgSO}_{4} \cdot 7 \mathrm{H}_{2} \mathrm{O}$ ) supplemented with $2 \mathrm{~g} / \mathrm{L}$ yeast extract and $9 \mathrm{~g} / \mathrm{L}$ glucose was used in a shake flask. Fed-batch cultures contained $3 \mathrm{~g} / \mathrm{L}$ $\mathrm{MgSO}_{4} \cdot 7 \mathrm{H}_{2} \mathrm{O}, 0.017 \mathrm{~g} / \mathrm{L} \mathrm{CaCl} 2 \cdot 2 \mathrm{H}_{2} \mathrm{O}, 1 \mathrm{~g} / \mathrm{L} \mathrm{NaCl}, 5 \mathrm{~g} / \mathrm{L}\left(\mathrm{NH}_{4}\right)_{2} \mathrm{SO}_{4}, 0.07 \mathrm{~g} / \mathrm{L} \mathrm{FeSO}{ }_{4} \cdot 7 \mathrm{H}_{2} \mathrm{O}, 0.11 \mathrm{~g} / \mathrm{L} \mathrm{Na}$-citrate $2 \mathrm{H}_{2} \mathrm{O}, 2 \mathrm{~g} / \mathrm{L}$ yeast extract, $8 \mathrm{~g} / \mathrm{L} \mathrm{glucose}$ and $1.5 \mathrm{~mL} / \mathrm{L} 1000 \times$ mother liquor of a composite additive of trace elements $\left(7 \mathrm{~g} / \mathrm{L} \mathrm{CoCl}_{2} \cdot 6 \mathrm{H}_{2} \mathrm{O}, 2.5 \mathrm{~g} / \mathrm{L} \mathrm{CuSO} \cdot 5 \mathrm{H}_{2} \mathrm{O}, 25 \mathrm{~g} / \mathrm{L} \mathrm{H} \mathrm{BO}_{3}, 16 \mathrm{~g} / \mathrm{L} \mathrm{MnCl} \cdot 4 \mathrm{H}_{2} \mathrm{O}\right.$, $1.5 \mathrm{~g} / \mathrm{L} \mathrm{Na}_{2} \mathrm{MoO}_{4} \cdot 2 \mathrm{H}_{2} \mathrm{O}$, and $\left.3 \mathrm{~g} / \mathrm{L} \mathrm{ZnSO}{ }_{4} \cdot 7 \mathrm{H}_{2} \mathrm{O}\right)$.

Plasmid DNA was isolated using a Plasmid Mini-Prep Kit (BIO Basic Inc) Chromosomal DNA from E. coli W3110 was isolated by using a Genomic DNA Isolation Kit (BIO Basic Inc). Agarose gel purification of DNA fragments was performed using a TaKaRa Agarose Gel DNA Purification Kit Ver. 2.0 (TAKARA BIOTECHNOLOGY CO). Restriction enzymes, ligases and other DNA manipulation enzymes were used according to the manufacturer's manuals (TAKARA BIOTECHNOLOGY CO). All plasmid constructs were verified by DNA sequencing (BIO Basic Inc). Plasmid DNA was transformed into competent E. coli cells by electroporation.

\subsection{Construction of gene knockout mutants}

Genes were knocked out singly or in combination using the method reported by Kirill A. Datsenko and Barry L. Wanner[15]. The primers used for amplification of the kanamycin cassette from the plasmid pKD4 are shown in Table S1, Additional file 2. The plasmids helper pKD13, pKD46 and pCP20 were used for construction of knockout mutants. All gene knockout strains were verified by sequencing with primers shown in Table S2, Additional file 3.

\subsection{Construction of the glyA mutant library}

Random mutagenesis was induced by error-prone PCR, and the mutation rate was controlled at $0.66 \%$. Genomic DNA of E. coli W3110 was utilized as the template with the primers glyA-F/R (Table 3). PCR reagents were mixed in a volume of $50 \mu \mathrm{L}$ according to the following composition: $10 \times$ reaction buffer, $10 \mathrm{pmol}$ each primer, $2 \mu \mathrm{mol} \mathrm{MnCl}_{2}, 2 \mu \mathrm{mol} \mathrm{MgCl}, 1 \mu \mathrm{mol}$ Taq DNA polymerase and unbalanced dNTPs. PCR products were purified and digested with Ndel and Hind III and were then subcloned into the expression vector pT 7-7. BL21(DE3) cell transformed with these expression vectors grew in LB at $30{ }^{\circ} \mathrm{C}$. Sequentially, the glyA sequence in pT7-7-glyA was replaced with these different glyA mutation constructs using site-directed mutagenesis with primers shown in Table S3, Additional file 4.

\subsection{Chromosomal integration of glymut constructs}

Pcas and PtargetF[16] were synthesized by GenScript (Nanjing, China).The sgRNA primer, including N20 sequences followed by the protospacer adjacent motif (PAM) sequence and donor DNA primer, glyA-D, used in this study are shown in Table 3. Genes were replaced using the method reported by Yu Jiang et al[16]. All gene knockout strains were verified by sequencing.

\subsection{Plasmid construction for overexpression of L-serine biosynthetic pathway components}

All plasmids used for plasmid construction are described in Table 2. The low copy number vector SP is a laboratory stock plasmid and contains the temperature-sensitive lambda repressor cltS857 gene and the lambda PR and PL promoters. The vector SP was used as the backbone for all plasmids constructed in this study. The L-Ser biosynthetic genes serA, serB and serC were amplified from E. coli W3110 using the primers shown in Table 3 . The 
ser $A^{f r}$ mutant was generated by mutating two residues in serA, His344 and Asn346, to alanines by site-directed mutagenesis with the primers shown in Table 3. SerA-p1 and serA-p2 were used to clone serAfr into the Xba l/ Nhe I site in SP under the control of the PL promoter, yielding the plasmid SP-01. This plasmid was later used to clone serC, generating SP-02. The gene serB was cloned into the SP-02 vector at the Bg/II and Sca I site, generating SP-05. Subsequently, the gene $p g k$, encoding phosphoglycerate kinase, was cloned into the SP-05 vector backbone, yielding the vector SP-08. The gene thrE, encoding the L-Ser/L-threonine exporter, was amplified from C.glutamicum ATCC 13032. And the resulting 1.7-kb fragment was cloned into the corresponding restriction sites in SP-08, generating in the vector SP-09.

\subsection{PGDH and SHMT enzyme assays}

BL21(DE3)/pT7-7-serA fr cells were harvested at mid-exponential growth phase through centrifugation after induction by isopropyl-beta-Dthiogalactopyranoside (IPTG), and crude extracts were obtained using ultrasonication. PGDH in crude extracts was purified by ion exchange chromatography (AKTA) on a Sepharose Fast Flow column, and diethylaminoethyl dextran gel (DEAE) was used as the anion exchange agent[17]. PGDH activity was determined by determination of a-ketoglutarate $(\mathrm{a}-\mathrm{KG})$ reductase activity instead of glyceric acid-3-phosphate dehydrogenase activity. The 1$\mathrm{mL}$ reaction system contained $40 \mathrm{mmol} / \mathrm{L}$ potassium phosphate buffer $(\mathrm{pH}=7.5), 1.0 \mathrm{mmol} / \mathrm{L}$ DL-dithiothreitol (DTT), $0.25 \mathrm{mmol} / \mathrm{L} \mathrm{NADH,} 5 \mathrm{mmol} / \mathrm{L} \mathrm{a-}$ KG and $10-30 \mu \mathrm{g}$ of the purified crude extract[18].

BL21(DE3)/pT7-7-gly $A^{\text {mut }}$ growth was induced by IPTG at an $\mathrm{OD}_{600}$ of 0.5 , and the culture was centrifuged to obtain bacterial cells at an $0 \mathrm{D}_{600}$ of 4 . SHMT activity was determined by a continuous spectrophotometric assay using DL-3-phenylserine hydrate and phosphopyridoxal as substrates[19] Hydrolysis of DL-3-phenylserine hydrate by SHMT was monitored spectrophotometrically at $279 \mathrm{~nm}$ to assess the formation of benzaldehyde. The standard curve was generated with a benzaldehyde concentration gradient by spectrophotometry $279 \mathrm{~nm}$ in the dark. The assay buffer contained $1 \mathrm{mg}$ of centrifuged bacterial cells and $1 \mathrm{~mL}$ of substrate $(50 \mathrm{mmol} / \mathrm{L} \mathrm{DL}-3$-phenylserine hydrate, $30 \mu \mathrm{mol} / \mathrm{L}$ phosphopyridoxal, $\mathrm{pH}=8.0)$ at $37{ }^{\circ} \mathrm{C}$. After culture at $30^{\circ} \mathrm{C}, 200 \mathrm{rpm}$ for $1 \mathrm{~h}$, the assay buffer was centrifuged at $5000 \mathrm{rpm}$ for 10 minutes, and the supernatants were evaluated at $279 \mathrm{~nm}$. The production of $1 \mathrm{~mol}$ of benzaldehyde per hour with $1 \mathrm{~g}$ wet weight of the cell in $1 \mathrm{~L}$ assay buffer buffer was defined as one unit.

\subsection{Shake flask and fed-batch fermentation}

For shake flask studies, a single clone was first grown in $5 \mathrm{~mL}$ of LB for $12-14 \mathrm{~h}$, and $5 \mathrm{~mL}$ of the culture was transferred to $100 \mathrm{~mL}$ of $\mathrm{M} 9 \mathrm{medium}$ with supplemented $2 \mathrm{~g} / \mathrm{L}$ yeast extract and $9 \mathrm{~g} / \mathrm{L}$ glucose for culture in a $500-\mathrm{mL}$ shake flask at $30^{\circ} \mathrm{C}$ and $200 \mathrm{rpm}$. Each culture was induced after $3 \mathrm{~h}$ by heating to $38^{\circ} \mathrm{C}$. The shake flask studies were repeated at least three times.

Fed-batch fermentation was conducted in a 5-L bioreactor (Biostat A Plus, Sartorius Stedim, Germany). A single clone was precultured in $50 \mathrm{~mL}$ of LB and shaken at $33^{\circ} \mathrm{C}$ and $200 \mathrm{rpm}$ for 12 to $14 \mathrm{~h}$. The culture was inoculated into $2.5 \mathrm{~L}$ of fermentation medium at a 1:20 (v/v) inoculum:medium ratio atan initial temperature of $33^{\circ} \mathrm{C}$. L-Ser production was induced at an $\mathrm{OD}_{600}$ of 20 by heating to $38^{\circ} \mathrm{C}$. The agitation, air supplementation and feed rate were changed to maintain the dissolved oxygen (DO) concentration above $30 \%$ saturation. The $\mathrm{pH}$ was controlled at $6.8 \mathrm{using} 30 \%(\mathrm{w} / \mathrm{v}) \mathrm{NH}_{3} \cdot \mathrm{H}_{2} \mathrm{O}$. The $\mathrm{DO}$-stat feeding strategy was employed to supply exhausted nutrients to the fermenter. The feeding solution contained 40\% (w/w) glucose.

\subsection{Sample preparation and extraction for intermediate metabolite analysis}

Bioreactor-grown cells were harvested at exponential growth phase after induction. $5 \mathrm{~mL}$ of culture was injected into the $20 \mathrm{~mL}$ quenching solutions (glycerol/saline, $60 / 40, \mathrm{v} / \mathrm{v}$ ) and directly centrifuged at $12,00 \mathrm{rpm}$ at $-20^{\circ} \mathrm{C}$ for $3 \mathrm{~min}$. After the removal of the supernatant, cell pellets were resuspended by $5 \mathrm{~mL}$ saline and cells were collected by centrifugation at $12,00 \mathrm{rpm}$ at $-20^{\circ} \mathrm{C}$ for $3 \mathrm{~min}$. Subsequently, cell pellets were extracted three times by cold methanol as reported previously[20]. Cell debris was removed by centrifugation for 5 min at 12,000 rpm.

\subsection{Analytical methods}

Bacterial growth was monitored by measuring the $\mathrm{OD}_{600}$ in a spectrophotometer (Beckman Germany), and the glucose concentration was analyzed using an SBA sensor machine (Institute of Microbiology, Shandong, China). The L-Ser from fermentation solution was determined by precolumn derivatization HPLC as follows. Two hundred microliters of cell-free supernatants, $100 \mu \mathrm{L} 1 \mathrm{~mol} / \mathrm{L}$ triethylamine (TEA, with acetonitrile as the solvent) and $100 \mu \mathrm{L}$ of $0.2 \mathrm{~mol} / \mathrm{L}$ phenylisothiocyanate (PITC, with acetonitrile as the solvent) were added to into a $1.5-\mathrm{mL}$ microcentrifuge tube. Then, $400 \mu \mathrm{L}$ of $\mathrm{n}$-hexane was added to the tube and incubated at room temperature for $1 \mathrm{~h}$. Then, the lower solution layer $(200 \mu \mathrm{L})$ was mixed with $800 \mu \mathrm{L}$ of deionized water and filtered through a 0.22- $\mu \mathrm{m}$ PTFE membrane filter (Hydrophilic PTFE Syringe Filter, ANPEL Laboratory Technologies Inc.) [21]. Finally, the filtrates were used for HPLC analysis with a Shimadzu Separations module connected to a Shimadzu SPD-M20A detector set to $256 \mathrm{~nm}$ and were separated on an Agilent Extend C-18 column $(250 \mathrm{~mm} \times 4.6 \mathrm{~mm}, 5 \mu \mathrm{m})$ using $0.05 \mathrm{~mol} / \mathrm{L}$ sodium acetate $(\mathrm{pH}=6.50 \pm 0.05)$ (mobile phase A) and methanol:acetonitrile:water $(20: 60: 20, \mathrm{v} / \mathrm{v} / \mathrm{v})$ (mobile phase $\mathrm{B}$ ) with a flow rate of $0.8 \mathrm{~mL} / \mathrm{min}$, a constant column temperature of $45^{\circ} \mathrm{C}$. The gradient time course was as follows: initial condition, $A: B(93: 7, v / v) ; 13$ minutes, $A: B(0: 100, v / v) ; 19$ minutes, $A: B(93: 7, v / v) ; 25$ minutes, completed elution.

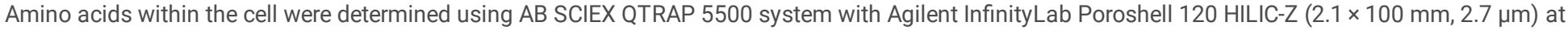
$35^{\circ} \mathrm{C}$. Conditions of mass spectrometer were as follows: curtain gas, $35 \mathrm{psi}$; ion source gas $1,60 \mathrm{psi}$; ion source gas 2,60 psi; source temperature, $550^{\circ} \mathrm{C}$; polarity, positive; ionspray voltage, $5500 \mathrm{~V}$. Mobile phase A was $20 \mathrm{mM}$ ammonium formate in water at pH 3 whereas mobile phase B consisted of $20 \mathrm{mM}$ aqueous ammonium foramte at $\mathrm{pH} 3$ in acetonitrile/water $(9: 1, \mathrm{~V} / \mathrm{V})$. The flow rate of the mobile phase was $0.25 \mathrm{~mL} / \mathrm{min}$. The gradient time course was as follows: initial condition, $A: B(5: 95, v / v) ; 15$ minutes, $A: B(35: 65, v / v) ; 17$ minutes, $A: B(35: 65, v / v) ; 18$ minutes, $A: B(5: 95$, v/v); 20 minutes, completed elution. 
Organic acids within the cell were determined using AB SCIEX QTRAP 5500 system with WATERS T3 column $(4.6 \times 150 \mathrm{~mm}, 3 \mu \mathrm{m})$ at $40{ }^{\circ} \mathrm{C}$. Conditions of mass spectrometer were as follows: curtain gas, $35 \mathrm{psi}$; ion source gas 1, $55 \mathrm{psi}$; ion source gas 2,55 psi; source temperature, $550^{\circ} \mathrm{C}$; polarity, negative; ionspray voltage, $4500 \mathrm{~V}$. Mobile phase A was $0.1 \%$ formic acid in acetonitrile whereas mobile phase B consisted of $0.1 \%$ formic acid in water. The flow rate of the mobile phase was $0.3 \mathrm{~mL} / \mathrm{min}$. The gradient time course was as follows: initial condition, $A: B(2: 98, v / v) ; 2 \mathrm{minutes}, A: B(2: 98, v / v) ; 6$ minutes, $A: B(98: 2, v / v) ; 9$ minutes, $A: B(98: 2, v / v) ; 9.1$ minutes, $A: B(2: 98, v / v) ; 13.5$ minutes, completed elution.

\subsection{Transcriptome data sets}

For transcriptome analysis, we only used the transcriptome data sets that were obtained at the exponential growth phase after induction. The samples were frozen immediately in liquid nitrogen and sent to Sangon Biotech (Shanghai, China) for transcriptome sequencing. Differentially expressed genes (DEGs) were identified according to the following rules: a log2 fold change (FC) $>2$ and a $p$ value $<0.05[22]$.

\section{List Of Abbreviations}

$\mathrm{Glc}_{\mathrm{ex}}$, extracellular glucose;

PEP, phosphoenolpyruvate;

PYR, pyruvic acid;

ATP, adenosine triphosphate;

ADP, adenosine diphosphate;

G6P, glucose-6-phosphate;

F6P, fructose-6-phosphate;

F-1,6-BP, fructose-1,6-bisphosphate;

GA3P, glyceraldehyde-3-phosphate;

1,3-PG, 1,3-bisphosphoglycerate;

3-PG, 3-phosphoglycerate;

2-PG, 2-phosphoglycerate;

AcCoA, acetyl-CoA;

Cit, citric acid;

cis-Aco, cis-aconitic acid;

ICit, isocitric acid;

2-0x0, 2-oxoglutarate;

SucCoA, succinyl-CoA;

Suc, succinic acid;

Fum, fumaric acid;

Mal, malic acid;

OAA, oxaloacetic acid囚

$\mathrm{NAD}^{+}$, oxidized nicotinamide adenine dinucleotide;

$\mathrm{NADH}$, reduced nicotinamide adenine dinucleotide;

NADP, oxidized nicotinamide adenine dinucleotide phosphate;

$\mathrm{NADPH}$, reduced nicotinamide adenine dinucleotide phosphate.

3-PHP, 3-phosphonooxypyruvate; 
L-Ser, L-serine;

D-Ser, D-serine;

L-Leu, L-leucine;

L-lle, L-isoleucine;

L-Val, L-valine;

Gly, glycine;

L-GIn, L-glutamine;

L-Glu, L-glutamate $\rrbracket$

THF, tetrahydrofolate;

MTHF, 5,10-methylene tetrahydrofolate;

LPL, lipoylprotein;

DHP, dihydrolipoylprotein;

amDHP, aminomethyldihydrolipoylprotein.

\section{Declarations}

\section{Ethics approval and consent to participate}

Not applicable

\section{Consent for publication}

Not applicable

\section{Availability of data and material}

All data generated and analyzed during this study are included in this published article and its supplementary information files.

\section{Competing interests}

The authors declare that they have no competing interests.

\section{Funding}

This study was financially supported by National Natural Science Foundation of China (No. 31300048) and Science and Technology Planning Project of Shanghai Province of China (No. 19391903100 and No. 20392003600).

\section{Author's contributions}

Chenyang Wang carried out the genes deletion and L-serine uptake activity assay. Chenyang Wang, Xiaojia Chen and Qinyu Li measured enzymes activities. Lei Wang helped analysis structure of enzyme. Chenyang Wang, Li Li and Xinxin Ma performed L-serine fermentation. Chenyang Wang, Junjun Wu and Zhijun Zhao analyzed the data. Chenyang Wang, Junjun Wu, Zhijun Zhao and Jiping Shi conceived the study and reviewed the manuscript.

All authors read and approved the final manuscript.

\section{Acknowledgements}

Not applicable 


\section{References}

1. Hemanshu Mundhada KS, Hanne Bjerre Christensen,, Nielsen AT: Engineering of High Yield Production of L-Serine in Escherichia Coli. Biotechnology and Bioengineering 2016, 113:807-816.

2. Wendisch VF: Metabolic engineering advances and prospects for amino acid production. Metab Eng 2020, 58:17-34.

3. Zhang X, Xu G, Shi J, Koffas MAG, Xu Z: Microbial Production of I-Serine from Renewable Feedstocks. Trends Biotechnol $2018,36: 700-712$.

4. Becker J, Wittmann C: Systems and synthetic metabolic engineering for amino acid production - the heartbeat of industrial strain development. Curr Opin Biotechnol 2012, 23:718-726.

5. Chao H, Wu B, Shen P: Overexpression of the methanol dehydrogenase gene mxaF in Methylobacterium sp. MB200 enhances L-serine production. Lett Appl Microbiol 2015, 61:390-396.

6. Peters-Wendisch P, Netzer R, Eggeling L, Sahm H: 3-Phosphoglycerate dehydrogenase from Corynebacterium glutamicum: the C-terminal domain is not essential for activity but is required for inhibition by L-serine. App/ Microbiol Biotechnol 2002, 60:437-441.

7. Peters-Wendisch P, Stolz M, Etterich H, Kennerknecht N, Sahm H, Eggeling L: Metabolic engineering of Corynebacterium glutamicum for L-serine production. Appl Environ Microbiol 2005, 71:7139-7144.

8. Stolz M, Peters-Wendisch P, Etterich H, Gerharz T, Faurie R, Sahm H, Fersterra H, Eggeling L: Reduced folate supply as a key to enhanced L-serine production by Corynebacterium glutamicum. Appl Environ Microbiol 2007, 73:750-755.

9. Zhu Q, Zhang X, Luo Y, Guo W, Xu G, Shi J, Xu Z: L-Serine overproduction with minimization of by-product synthesis by engineered Corynebacterium glutamicum. Appl Microbiol Biotechnol 2015, 99:1665-1673.

10. Sathesh-Prabu, Chandran Kim, Donghyuk Lee, Kuk S: Metabolic engineering of Escherichia coli for 2,3-butanediol production from cellulosic biomass by using glucose-inducible gene expression system. Bioresource Technology 2020, 309:123361.

11. Burgard AP, Maranas CD: Probing the Performance Limits of the Escherichia coli Metabolic Network Subject to Gene Additions or Deletions. Biotechnology and bioengineering 2001, 74:364-375.

12. Mundhada H, Seoane JM, Schneider K, Koza A, Christensen HB, Klein T, Phaneuf PV, Herrgard M, Feist AM, Nielsen AT: Increased production of Lserine in Escherichia coli through Adaptive Laboratory Evolution. Metab Eng 2017, 39:141-150.

13. Rennig M, Mundhada H, Wordofa GG, Gerngross D, Wulff T, Worberg A, Nielsen AT, Norholm MHH: Industrializing a Bacterial Strain for I-Serine Production through Translation Initiation Optimization. ACS Synth Bio/ 2019, 8:2347-2358.

14. Bin Zhang, Li-Quan Ren, Miao Yu Y, ing Zhou, Ye B-C: Enhanced I-ornithine production by systematic manipulation of I-ornithine metabolism in engineered Corynebacterium glutamicum S9114. Bioresour Technol 2018, 250:60-68.

15. Datsenko KA WB: One-step inactivation of chromosomal genes in Escherichia coli K-12 using PCR products. Proc Natl Acad Sci USA 2000, 97:66406645.

16. Jiang Y, Chen B, Duan C, Sun B, Yang J, Yang S: Multigene editing in the Escherichia coli genome via the CRISPR-Cas9 system. App/ Environ Microbiol 2015, 81:2506-2514.

17. ZHAO G, WINKLER ME: A Novel a-Ketoglutarate Reductase Activity of the serA-Encoded 3-Phosphoglycerate Dehydrogenase of Escherichia coli K-12 and Its Possible Implications for Human 2-Hydroxyglutaric Aciduria. JOURNAL OF BACTERIOLOGY, 1996:232-239.

18. Schuller DJ, GrantZ GA, Banaszak LJ: The allosteric ligand site in the Vmax-type cooperative enzyme phosphoglycerate dehydrogenase. Structural Biology 1995, 2:69-76.

19. Hsiao TKLaH-y: Synthesis of L-tyrosine by a coupled reaction of serine hydroxymethyltransferase and ./3-tyrosinase. Enzyme Microb Techno/ 1986 , 9:523-526.

20. Mei H, Dai J, Li W, Ling X, Zhu P, Zhao Z: Comparison of Extraction Methods for E. coli Metabolome Analysis Using Liquid Chromatography Tandem. Chinese Journal of Analytical Chemistry 2011, 39:534-539.

21. Chen Q, Wang Q, Wei G, Liang Q, Qi Q: Production in Escherichia coli of poly(3-hydroxybutyrate-co-3-hydroxyvalerate) with differing monomer compositions from unrelated carbon sources. App/ Environ Microbio/ 2011, 77:4886-4893.

22. Lin Zhou, Dujia Cheng, Liang Wang, Juan Gao, Zhao Q, Wei W, Sun Y: Comparative transcriptomic analysis reveals phenol tolerance mechanism of evolved Chlorella strain. Bioresour Technol 2017, 227:266-272.

23. Grant GA, Hu Z, Xu XL: Identification of Amino Acid Residues Contributing to the Mechanism of Cooperativity in Escherichia coli D-3Phosphoglycerate Dehydrogenase. Biochemistry 2005, 44:16844-16852.

24. Grant GA: D-3-Phosphoglycerate Dehydrogenase. Front Mol Biosci 2018, 5:110.

25. Ito T, Hori R, Hemmi H, Downs DM, Yoshimura T: Inhibition of glycine cleavage system by pyridoxine 5'-phosphate causes synthetic lethality in glyA yggS and serA yggS in Escherichia coli. Molecular Microbiology 2019, 113:270-284.

26. Xiaomei Zhang, Lianhe Lai, Guoqiang Xu, Xiaojuan Zhang, Jinsong Shi, Mattheos A. G. Koffas, Xu Z: Rewiring the Central Metabolic Pathway for High-Yield I-Serine Production in Corynebacterium glutamicum by Using Glucose. Biotechnol J 2019, 14:1-9.

27. Ye L, Zhao H, Li Z, Wu JC: Improved acid tolerance of Lactobacillus pentosus by error-prone whole genome amplification. Bioresour Techno/2013, 135:459-463. 
28. Bhavani S, Trivedi V, Jala VR, Subramanya HS, Kaul P, Prakash V, Rao NA, Savithri HS: Role of Lys-226 in the Catalytic Mechanism of Bacillus Stearothermophilus Serine HydroxymethyltransferasesCrystal Structure and Kinetic Studies. Biochemistry 2005, 44:6929-6937.

29. Li. Y, Chen. G-K, Zhang. H-T, Lu. F-P: Construction of Escherichia coli strains producing L-serine from glucose. Biotechnol Lett 2012, 34:1525-1530.

30. Burman JD, Harris RL, Hauton KA, Lawson DM, Sawers RG: The iron-sulfur cluster in the L-serine dehydratase TdcG from Escherichia coli is required for enzyme activity. FEBS Lett 2004, 576:442-444.

31. Zhang B, Zhang XM, Wang W, Liu ZQ, Zheng YG: Metabolic engineering of Escherichia coli for d-pantothenic acid production. Food Chem 2019, 294:267-275.

32. Liu Q, Cheng Y, Xie X, Xu Q, Chen N: Modification of tryptophan transport system and its impact on production of L-tryptophan in Escherichia coli. Bioresour Technol 2012, 114:549-554.

33. Li Y, Wei H, Wang T, Xu Q, Zhang C, Fan X, Ma Q, Chen N, Xie X: Current status on metabolic engineering for the production of I-aspartate family amino acids and derivatives. Bioresour Technol 2017, 245:1588-1602.

34. OGAWA W, KIM Y-M, MIZUSHIMA T, Microbiology Do: Cloning and Expression of the Gene for the Na冈-Coupled Serine Transporter from Escherichia coli and Characteristics of the Transporter. Journal of Bacteriology 1998, 180:6749-6752.

35. Schneider F, Kramer R, Burkovski A: Identification and characterization of the main beta-alanine uptake system in Escherichia coli. App/ Microbiol Biotechnol 2004, 65:576-582.

36. ZhongQi SHAO RTLaEBN: Sequencing and characterization of the sdaC gene and identification of the sdaCB operon in Escherichia coli K12. Eur J Biochem 1994, 222: 901-907.

37. Sumantran VN, Schweizer HP, Datta P: A Novel Membrane-Associated Threonine Permease Encoded by the tdcC Gene of Escherichia coli. Journal of Bacteriology 1990, 172:4288-4294

38. Wang C, Wu J, Shi B, Shi J, Zhao Z: Improving L-serine formation by Escherichia coli by reduced uptake of produced L-serine. Microb Cell Fact 2020, 19:66.

39. Simic P, Sahm H, Eggeling L: L-Threonine Export: Use of Peptides To Identify a New Translocator from Corynebacterium glutamicum. Journal of Bacteriology 2001, 183:5317-5324.

40. Yen M-R, Tseng Y-H, Simic P, Sahm H, Jr MHS: The ubiquitous ThrE family of putative transmembrane amino acid efflux transporters. Research in Microbiology 2002, 153:19-25.

41. J. FH, S. HM: The Tricarboxylic Acid Cycle. In Essentials of Biochemistry. Berlin, Heidelberg: Springer Berlin Heidelberg; 2012: $205-222$.

42. Hu J, Ma H, Zhang W, Yu Z, Sheng G, Fu J: Effects of benzene and its metabolites on global DNA methylation in human normal hepatic I02 cells. Environmental Toxicology 2014, 29:108-116.

43. Steinsiek S, Frixel S, Stagge S, Bettenbrock K: Characterization of E. coli MG1655 and frdA and sdhC mutants at various aerobiosis levels. Journal of Biotechnology 2011, 154:35-45.

44. Zhang Y, Shang X, Lai S, Zhang Y, Hu Q, Chai X, Wang B, Liu S, Wen T: Reprogramming One-Carbon Metabolic Pathways To Decouple I-Serine Catabolism from Cell Growth in Corynebacterium glutamicum. ACS Synth Biol 2018, 7:635-646.

45. Yao S, Chen L, Yang Z, Yao L, Zhu J, Qiu J, Wang G, He J: The Properties of 5-Methyltetrahydrofolate Dehydrogenase (MetF1) and Its Role in the Tetrahydrofolate-Dependent Dicamba Demethylation System in Rhizorhabdus dicambivorans Ndbn-20. Journal of Bacteriology 2019, 209:e0009600019.

46. Attia YA, Hassan RA, Qota EM: Recovery from adverse effects of heat stress on slow-growing chicks in the tropics 1: Effect of ascorbic acid and different levels of betaine. Trop Anim Health Prod 2009, 41:807-818.

47. SU Y-w, GUO Q-q, WANG S, ZHANG X, WANG J: Fed-Batch Fermentation of L-Threonine by Escherichia Coli Supplemented with B-Vitamins. Advances in Biological Sciences Research 2017, 4:285-291.

48. de Lorenzo V, Sekowska A, Danchin A: Chemical reactivity drives spatiotemporal organisation of bacterial metabolism. FEMS Microbiol Rev 2015, 39:96-119.

49. Knapik AA, Petkowski JJ, Otwinowski Z, Cymborowski MT, Cooper DR, Majorek KA, Chruszcz M, Krajewska WM, Minor W: A multi-faceted analysis of RutD reveals a novel family of alpha/beta hydrolases. Proteins 2012, 80:2359-2368.

50. Li L, Adachi M, Yu J, Kato K, Shinod A, Ostermann A, Schrader TE, Ose T, Yao M: Neutron crystallographic study of heterotrimeric glutamine amidotransferase CAB. Acta Crystallographica Section F Structural Biology Communications 2019, 75:193-196.

51. Zhang Y, Kang P, Liu S, Zhao Y, Wang Z, Chen T: glyA gene knock-out in Escherichia coli enhances L-serine production without glycine addition. Biotechnology and Bioprocess Engineering 2017, 22:390-396.

\section{Tables}


Table 1

Strains used in the experiment

\begin{tabular}{|c|c|c|}
\hline Strain & Relevant characteristics & Source \\
\hline E.coli DH5a & Cloned strains & TaKaRa \\
\hline E.coli BL21(DE3) & Expression strains & ATCC 26003 \\
\hline E.coli W3110 & Parental strains & ATCC 23275 \\
\hline SSW-01 & W3110 $\triangle s d a A$ & This work \\
\hline SSW-02 & W3110 $\triangle$ sdaA glyA & This work \\
\hline SSW-03 & W3110 $\triangle s d a A g l y A^{m u t}$ & This work \\
\hline SSW-05 & W3110 $\triangle$ sdaA gly $A^{m u t} s d a B$ & This work \\
\hline SSW-06 & W3110 $\triangle s d a A$ gly $A^{m u t} i l v A$ & This work \\
\hline SSW-07 & W3110 $\triangle s d a A g l y A^{m u t} t d c B$ & This work \\
\hline SSW-08 & W3110 $\triangle s d a A g l y A^{m u t} t d c G$ & This work \\
\hline SSW-10 & W3110 $\triangle$ sdaABC glyA $A^{m u t}$ & This work \\
\hline
\end{tabular}

Table 2

Plasmids used in the experiment

\begin{tabular}{|c|c|c|}
\hline Plasmid & Relevant characteristics & Source \\
\hline pT 7-7 & amp marker, T7 promoter & Takara \\
\hline pSC & Low copy number, kan marker, p15A replicon, lambda PR and PL promoters & Lab stock \\
\hline pKD13 & amp and kan markers & {$[15]$} \\
\hline pKD46 & amp marker, temperature-sensitive & [15] \\
\hline pCP20 & $a m p$ and $c h /$ makers, temperature-sensitive & [15] \\
\hline pMD19-T simple & amp maker, TA cloning vector, $2692 \mathrm{bp}$ & Takara \\
\hline Pcas & repA101(Ts) kan Pcas-cas9 ParaB-Red laclq Ptrc-sgRNA-pMB1 & [16] \\
\hline PtargetF & pMB1 aadA & [16] \\
\hline PtargetF-glyA & pMB1 aadA sgRNA-glyA & This work \\
\hline pT- serA & pT 7-7 derivative, carrying ser $A$ & This work \\
\hline pT- $\operatorname{ser} A^{\text {fr }}$ & pT 7-7 derivative, carrying serA & This work \\
\hline pT-glyA & pT 7-7 derivative, carrying $g / y A$ & This work \\
\hline pT-gly $A^{\text {mut }}$ & pT 7-7 derivative, carrying $g l y A^{m u t}$ & This work \\
\hline SP-01 & SP derivative, carrying $\operatorname{ser} A^{\text {fr }}$ & This work \\
\hline SP-02 & SP derivative, carrying $\operatorname{ser} A^{\mathrm{fr}}$, serC & This work \\
\hline SP-05 & SP derivative, carrying $\operatorname{ser} A^{\mathrm{fr}}$, $\operatorname{ser} C$ and $\operatorname{ser} B$ & This work \\
\hline SP-08 & SP derivative, carrying $\operatorname{ser} A^{\mathrm{fr}}$, ser $B$, serC and $p g k$ & This work \\
\hline SP-09 & SP derivative, carrying $\operatorname{ser} A^{\mathrm{fr}}$, ser $B, \operatorname{ser} C, p g k$ and thrE & This work \\
\hline
\end{tabular}


Gene expression primers used in the experiment

\begin{tabular}{|c|c|c|}
\hline Primer & Sequence $\left(5^{\prime}-3^{\prime}\right)$ a & $\begin{array}{l}\text { Restriction } \\
\text { enzyme }\end{array}$ \\
\hline $\begin{array}{l}\text { serA- } \\
\text { p1 }\end{array}$ & TCTAGAAAGAAGGAGATATACCATGGCAAAGGTATCGCTGGAG & Xbal \\
\hline $\begin{array}{l}\text { serA- } \\
\text { p2 }\end{array}$ & GAGCTCGTGAGTAAGGGTAAGGGAGGATTG & Sacl \\
\hline $\begin{array}{l}\text { serB- } \\
\text { p1 }\end{array}$ & AGATCTAAGAAGGAGATATACCATGCCTAACATTACCTGGTGCGACC & $B g / I I$ \\
\hline $\begin{array}{l}\text { serB- } \\
\text { p2 }\end{array}$ & AGTACTGGCTGATATCGGAGAGTTTCTGGAC & Sca I \\
\hline $\begin{array}{l}\text { serc- } \\
\text { p1 }\end{array}$ & AGATCTAAGAAGGAGATATACCATGGCTCAAATCTTCAATTTTAG & $B g / I I$ \\
\hline $\begin{array}{l}\text { serC- } \\
\text { p2 }\end{array}$ & CAGCTGTACGATCGGCTGAAAGCGTATAG & $p v u l l$ \\
\hline$p g k-\mathrm{p} 1$ & TCTAGAAAGAAGGAGATATACCATGTCTGTAATTAAGATGACCGATCTGG & Xbal \\
\hline pgk- p2 & GAGCTCTTGATGGAGTCAGTACCGACG & Sacl \\
\hline $\begin{array}{l}\text { thrE- } \\
\mathrm{p} 1\end{array}$ & AGTACTAAGAAGGAGATATACCATGTTGAGTTTTGCGACCCTTCG & Scal \\
\hline $\begin{array}{l}\text { thrE- } \\
\text { p2 }\end{array}$ & AGATCTAGATCTACATCAAAGTGACGCCGTCGAAG & Xba I \\
\hline \multicolumn{3}{|c|}{ Site directed mutagenesis primers used for mutation of serA } \\
\hline $\begin{array}{l}\text { serA- } \\
\text { p3 }\end{array}$ & GATGCACATCGCAGAAGCA & \\
\hline $\begin{array}{l}\text { serA- } \\
\text { p4 }\end{array}$ & GCCCGGACGTGCTTCTGCGATGTGCATC & \\
\hline \multicolumn{3}{|c|}{ glyA primers } \\
\hline glyA-F & GGAATTCCATATGTTAAAGCGTGAAATGAAC & Ndel \\
\hline glyA-R & CCCAAGCTT TTATGCGTAAACCGGGTAAC & 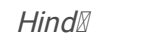 \\
\hline $\begin{array}{l}\text { sgRNA- } \\
\mathrm{F}\end{array}$ & TGGCAACCCACTTCAGCACCACTAGTATTATACCTAGGAC & \\
\hline $\begin{array}{l}\text { sgRNA- } \\
\mathrm{R}\end{array}$ & GGTGCTGAAGTGGGTTGCCAGTTTTAGAGCTAGAAATAGC & \\
\hline$\underset{\mathrm{F}}{g l y A-\mathrm{D}-}$ & TGTCCAACAGGACCGCCTATAAAGGCCAAAAATTTTATTGTTAGCTGAGTCAGGAGATGCGGATGTTAAAGCGTGAAATGAACATTG & \\
\hline$\underset{\mathrm{R}}{g l y A-\mathrm{D}-}$ & GGCGTTCACGCCGCATCCGGCATGAACAACGAGCACATTGACAGCAAATCACCGTTTCGCTTATGCGTAAACCGGGTAACG & \\
\hline
\end{tabular}


Table 4

SHMT activity of various mutants.

\begin{tabular}{|c|c|c|c|}
\hline Position & Sequence change & Protein change & SHMT activity \\
\hline- & - & - & $0.65 \pm 0.033^{a}$ \\
\hline 24 & $\mathrm{~T} \rightarrow \mathrm{G}$ & I8M(ATT $\rightarrow$ ATG $)$ & $0.63 \pm 0.022$ \\
\hline 88 & $\mathrm{~A} \rightarrow \mathrm{T}$ & I30F $($ ATC $\rightarrow$ TTC $)$ & $0.34 \pm 0.005$ \\
\hline 145 & $\mathrm{~T} \rightarrow \mathrm{A}$ & S49T $(\mathrm{TCT} \rightarrow \mathrm{ACT})$ & $0.58 \pm 0.005$ \\
\hline 149 & $\mathrm{~A} \rightarrow \mathrm{T}$ & $\mathrm{Q} 50 \mathrm{~L}(\mathrm{CAG} \rightarrow \mathrm{CTG})$ & $0.24 \pm 0.02$ \\
\hline 301 & $\mathrm{G} \rightarrow \mathrm{T}$ & $\mathrm{A} 101 \mathrm{~S}(\mathrm{GCT} \rightarrow \mathrm{TCT})$ & $0.22 \pm 0.016$ \\
\hline 483 & $\mathrm{~A} \rightarrow \mathrm{T}$ & $\mathrm{Q} 161 \mathrm{H}(\mathrm{CAA} \rightarrow \mathrm{CAT})$ & $0.66 \pm 0.018$ \\
\hline 532 & $\mathrm{~T} \rightarrow \mathrm{C}$ & $\mathrm{S} 178 \mathrm{P}(\mathrm{TCC} \rightarrow \mathrm{CCC})$ & $0.36 \pm 0.028$ \\
\hline 572 & $A \rightarrow C$ & $\mathrm{D} 191 \mathrm{~A}(\mathrm{GAC} \rightarrow \mathrm{GCC})$ & $0.6 \pm 0.019$ \\
\hline $685 / 686$ & $\mathrm{AA} \rightarrow \mathrm{GG}$ & $\mathrm{K} 229 \mathrm{G}(\mathrm{AAA} \rightarrow \mathrm{GGA})$ & $0.13 \pm 0.005$ \\
\hline 743 & $\mathrm{~T} \rightarrow \mathrm{G}$ & L248R(CTG $\rightarrow \mathrm{CGG})$ & $0.56 \pm 0.014$ \\
\hline 902 & $\mathrm{~T} \rightarrow \mathrm{G}$ & V301G(GTG $\rightarrow$ GGG) & $0.57 \pm 0.017$ \\
\hline 1073 & $\mathrm{~T} \rightarrow \mathrm{C}$ & V358A(GTG $\rightarrow$ GCG) & $0.54 \pm 0.01$ \\
\hline 1163 & $\mathrm{~A} \rightarrow \mathrm{T}$ & $\mathrm{D} 388 \mathrm{~V}(\mathrm{GAC} \rightarrow \mathrm{GTC})$ & $0.57 \pm 0.008$ \\
\hline 1195 & $\mathrm{~A} \rightarrow \mathrm{T}$ & I399F(ATC $\rightarrow$ TTC $)$ & $0.62 \pm 0.032$ \\
\hline 1225 & $A \rightarrow C$ & $1409 \mathrm{~L}(\mathrm{ATC} \rightarrow \mathrm{CTC})$ & $0.44 \pm 0.004$ \\
\hline 1238 & $A \rightarrow C$ & Y413S $($ TAC $\rightarrow$ TCC $)$ & $0.59 \pm 0.012$ \\
\hline
\end{tabular}

Figures 


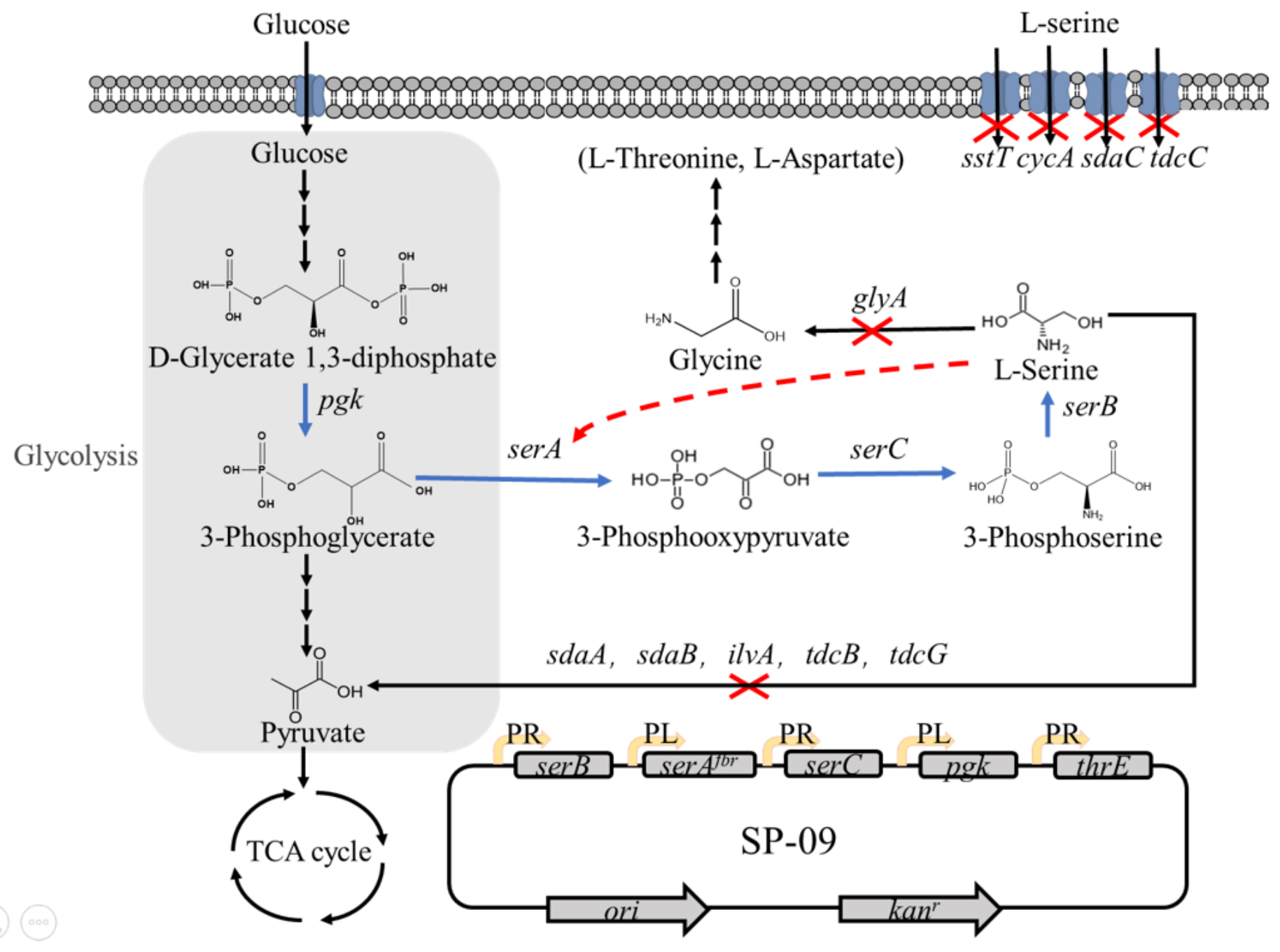

Figure 1

L-Serine biosynthesis and its regulation in E. coli. The blue arrows indicate overexpression of the relevant genes using the SP vector. The red " $\mathrm{X}$ " indicates deletion of relevant genes. The red dashed line indicates feedback inhibition. 
$\underline{\mathbf{A}}$
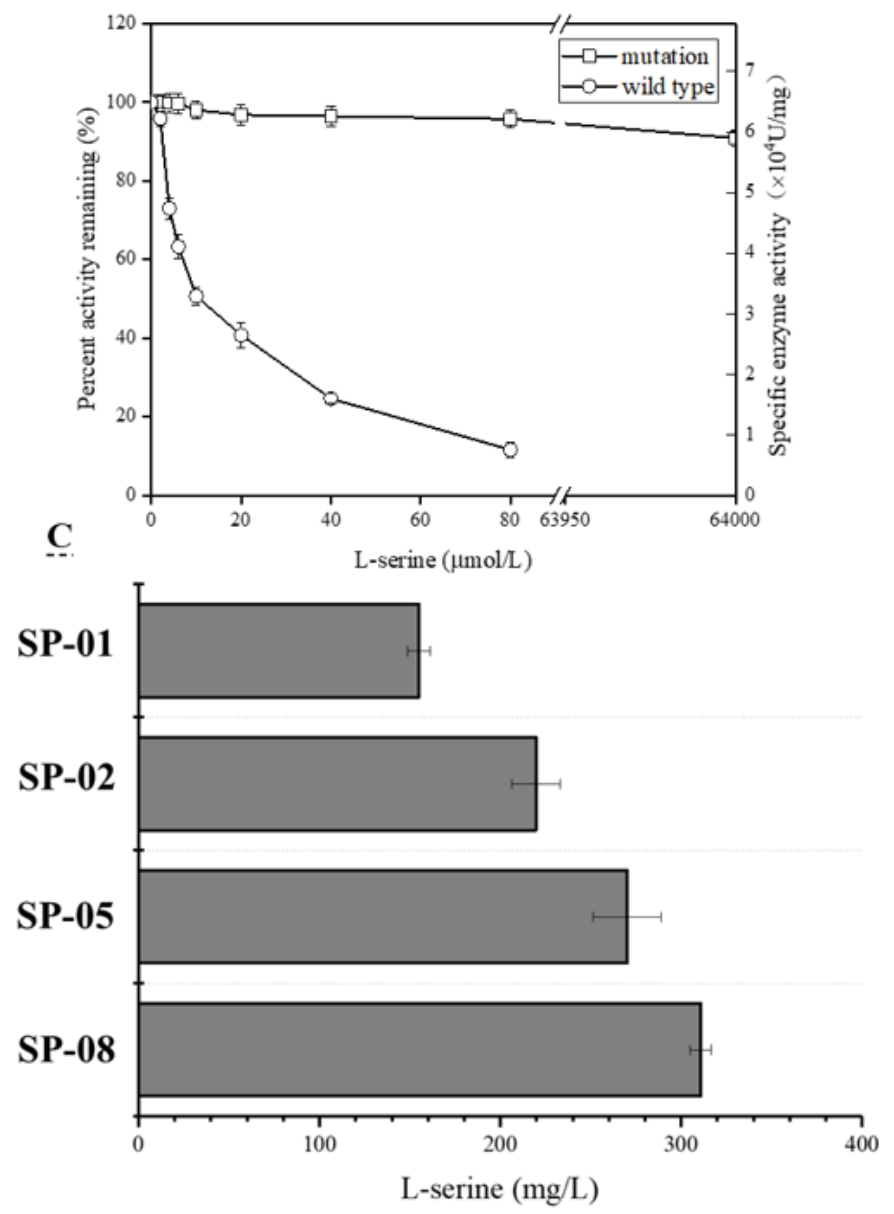

$\underline{B}$
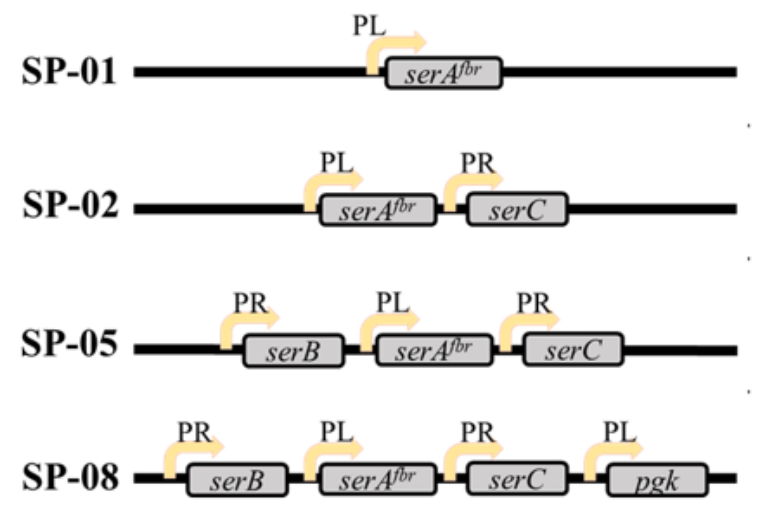

D

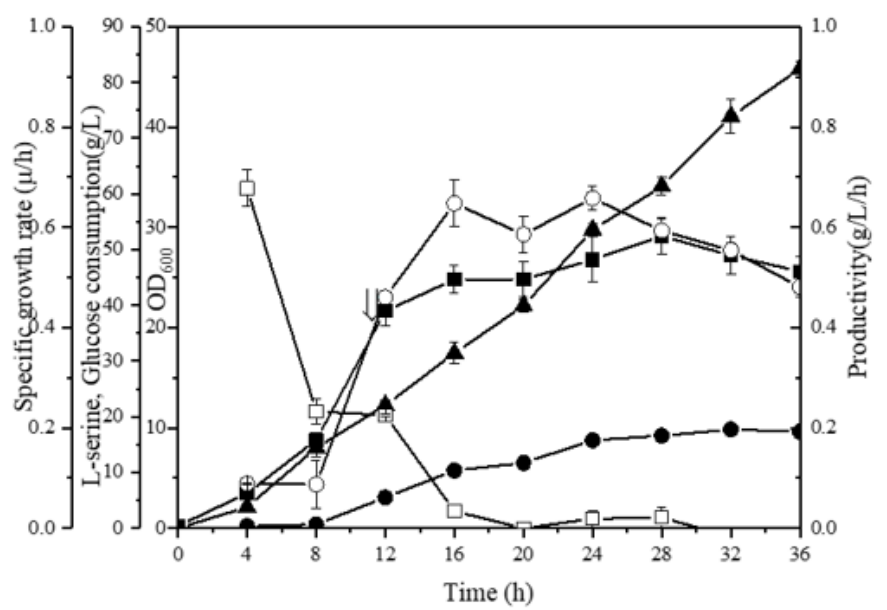

\section{Figure 2}

Optimization of the synthetic serAfrCB operon with pgk and screening for high-level L-serine production (A) PGDHmut (serAfr, open squares), PGDHwt (serA, open circles). (B)The structure of different plasmids. (C)L-serine production by shake flask fermentation with different plasmids. (D) L-serine production by SSW-02/SP-08 by fed-batch fermentation. Cell growth (filled squares), L-serine concentration (filled circles), glucose consumption (upwardpointing filled triangles), specific growth rate (open squares), and L-serine productivity (open circles). The arrow indicates the starting point of induction. The data are presented as the means \pm SDs from three measurements.

A

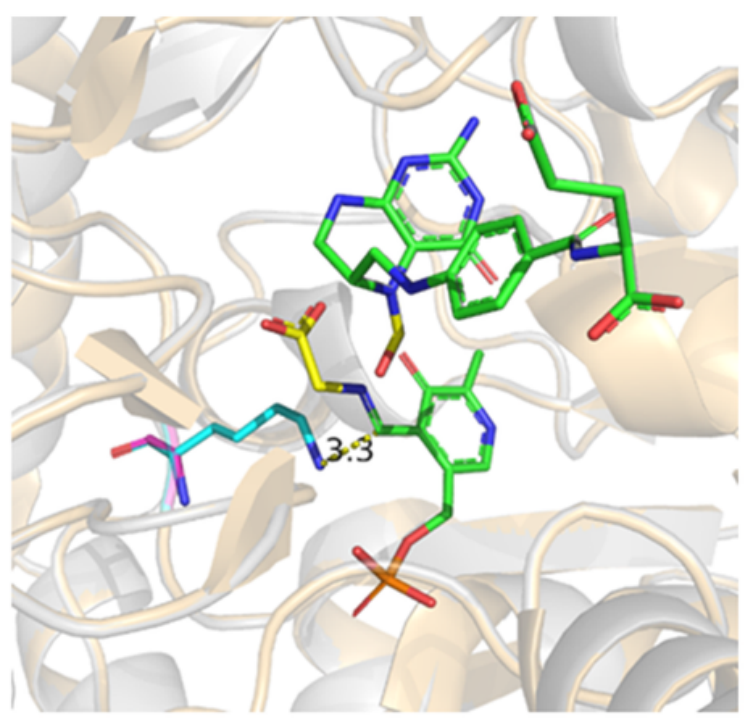

B

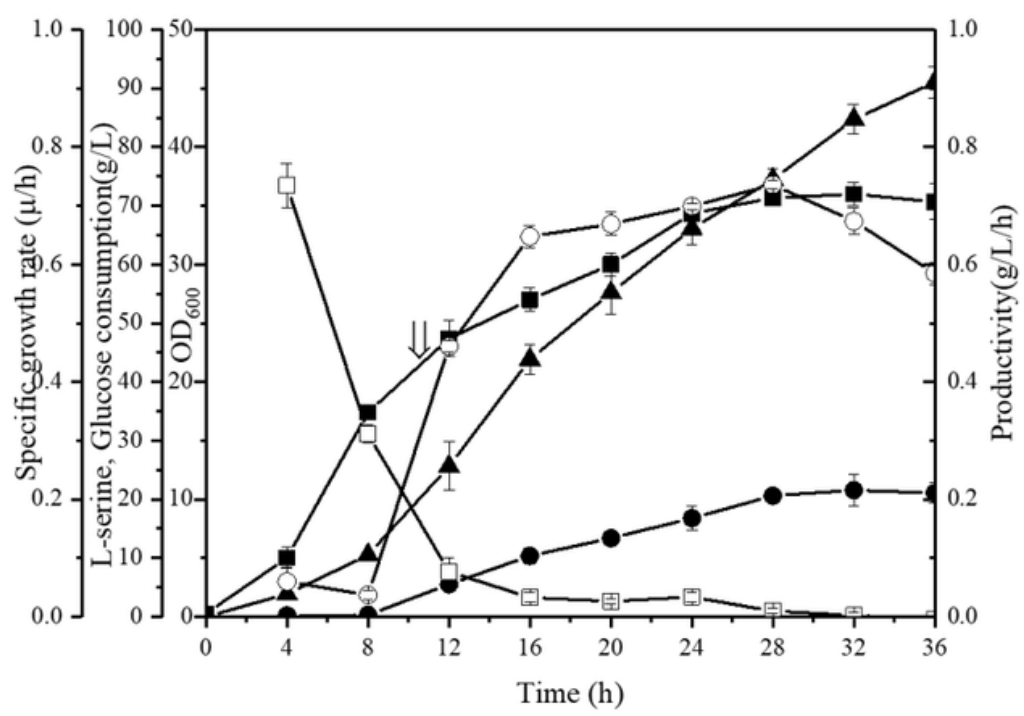


Figure 3

SSW-03/SP-08 L-serine production during fed-batch fermentation. (A) Structural modelling of SHMT mutant K229G (light gray) and comparison with the wild-type (light orange, PDB ID, 1DFO) in cartoon format. The cofactor PLP and THFA are sticks in green. The L-serine degradation products glycine and formyl group are sticks in yellow. K229 of the wild-type is stick in cyan and G229 of mutant is stick in magenta. The $\mathrm{O}$ is in red and the $\mathrm{N}$ is in blue. (B) SSW-03/SP-08 L-serine production by fed-batch fermentation. Cell growth (filled squares), L-serine concentration (filled circles), glucose consumption (upward-pointing filled triangles), specific growth rate (open squares), and L-serine productivity (open circles). The arrow indicates the starting point of induction. The data are presented as the means \pm SDs from three measurements.

\section{A}

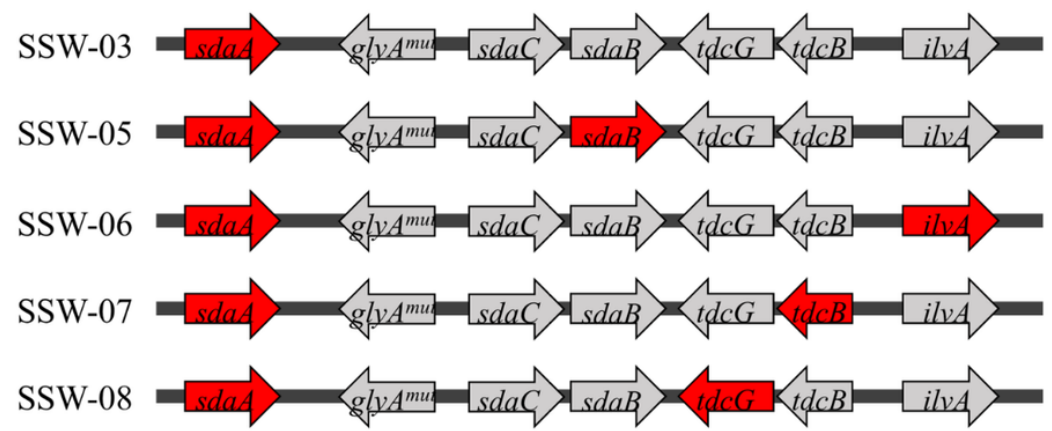

B

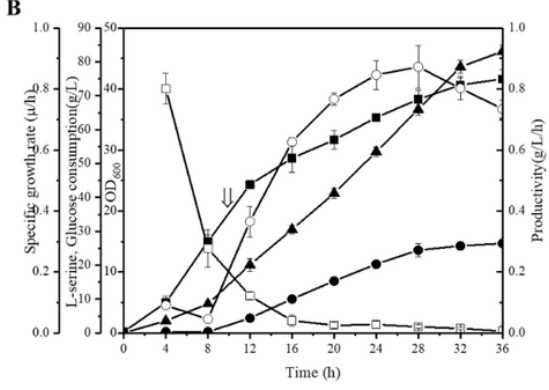

D

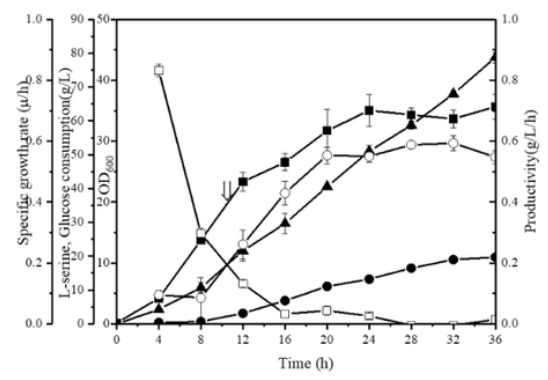

C

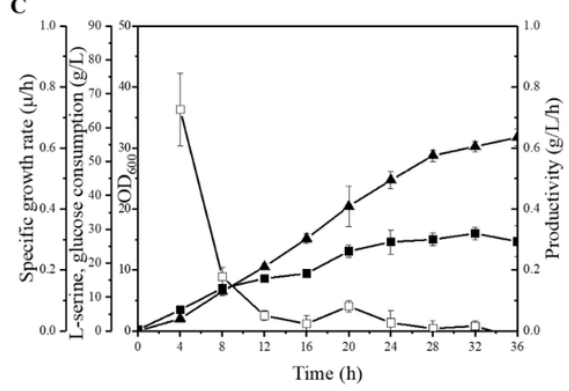

E

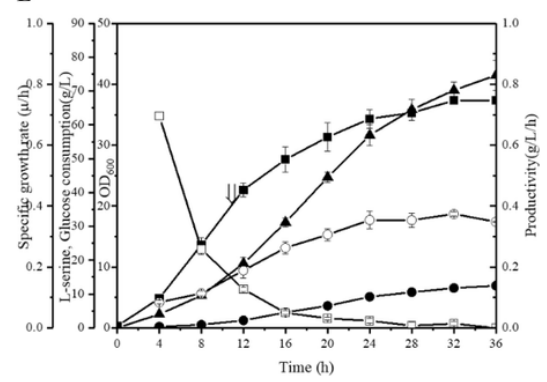

Figure 4

Effect of sdaB, ilvA, tdcB or tdcG deletion on L-serine production and biomass. (A) Genotypes of the strains. The genes marked in red indicate targets for knockout. (B) L-serine production by and growth of SSW-05/SP-08 cells. (C) Cell density achieved by SSW-06/SP-08. (D) L-serine production by and growth of SSW-07/SP-08 cells. (E) L-serine production and cell density achieved by SSW-08/SP-08. Cell growth (filled squares), L-serine concentration (filled circles), glucose consumption (upward-pointing filled triangles), specific growth rate (open squares), and L-serine productivity (open circles). The arrow indicates the starting point of induction. The data are presented as the means \pm SDs from three measurements. 
A

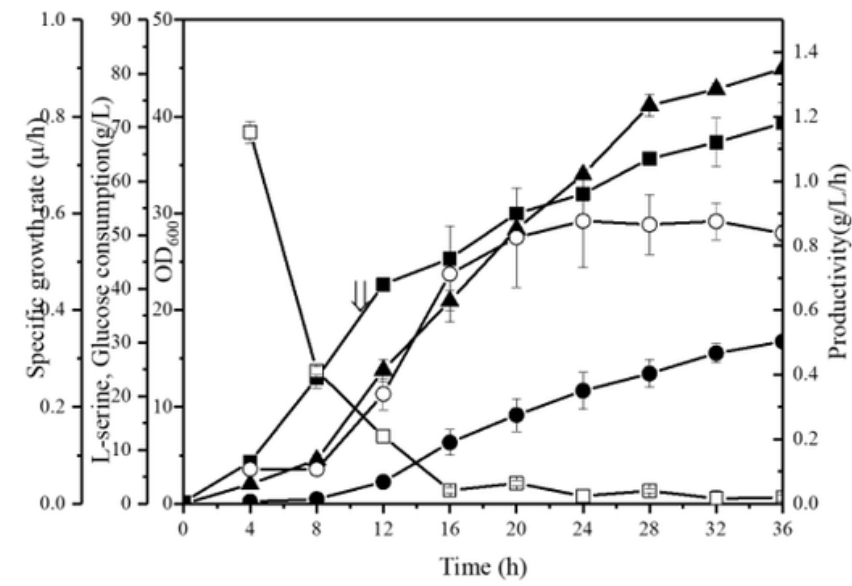

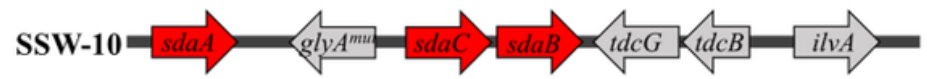

B

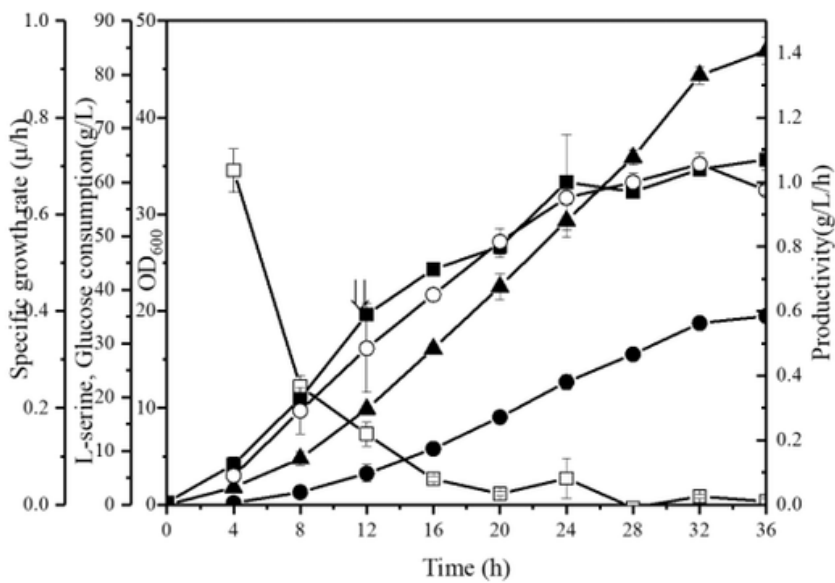

PR
PL

PR

SP-09

PL

$\operatorname{ser} A^{\beta r}$

Figure 5

L-serine production by SSW-10/SP-08 and SSW-10/SP-09 during fed-batch fermentation. (A) Genotype of strain SSW-10 and structures of different SP-09 plasmids. The genes marked in red indicate targets for knockout. (B) L-serine production by and growth of SSW-011/SP-08 cells. (C) L-serine production and cell density achieved by SSW-011/SP-09. Cell growth (filled squares), L-serine concentration (filled circles), glucose consumption (upward-pointing filled triangles), specific growth rate (open squares), and L-serine productivity (open circles). The arrow indicates the starting point of induction. The data are presented as the means \pm SDs from three measurements.

A

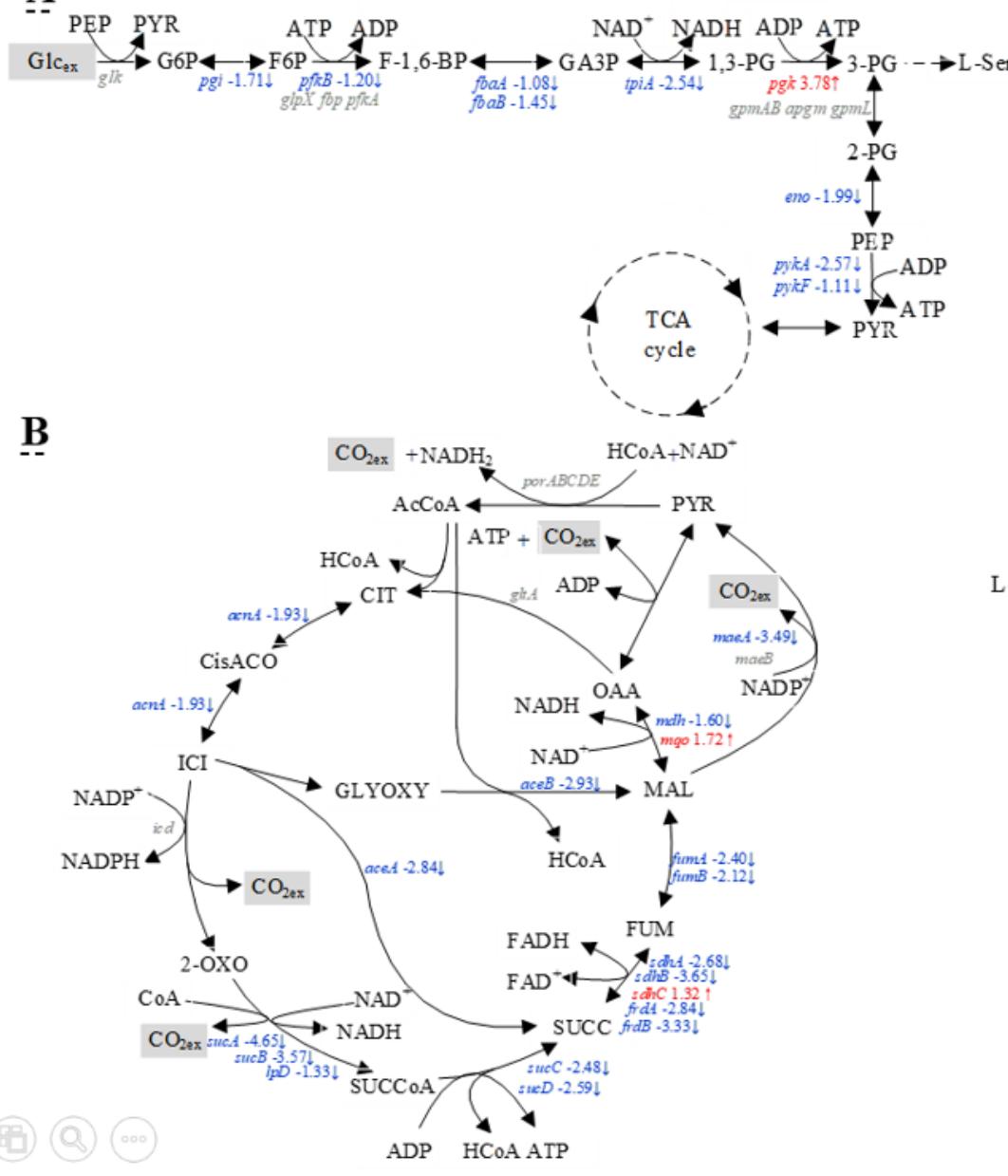

C.

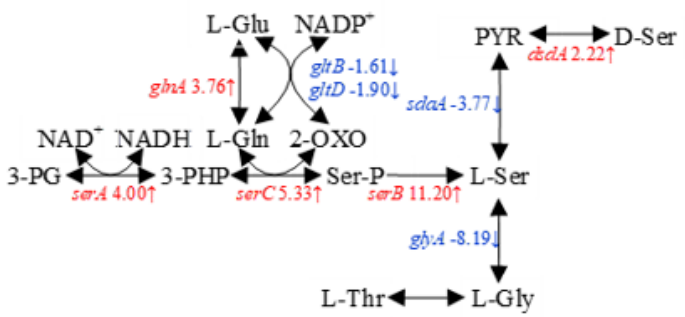

$\underline{\mathbf{D}}$

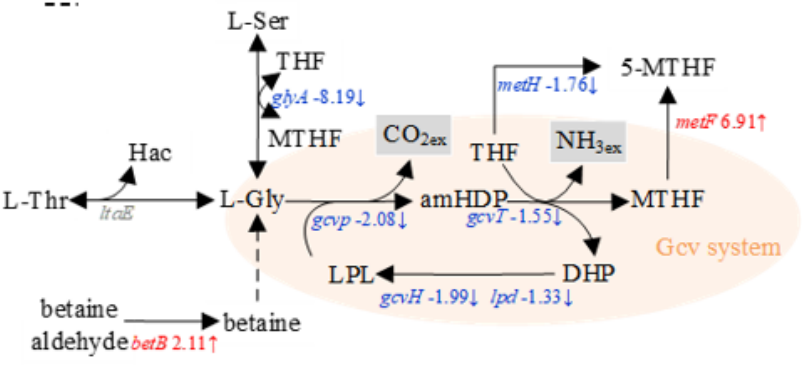

$\underline{\mathbf{E}}$

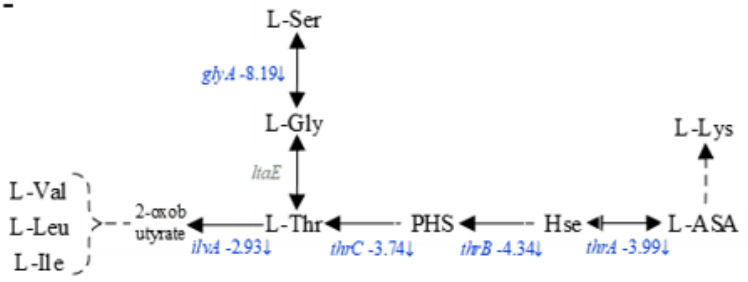

Figure 6 
Gene expression levels related to the glycolysis, TCA cycle and amino acid pathways related L-Ser synthesis. (A)Glycolysis, (B) TCA cycle, (C) L-serine, (D) L-glycine and (E) L-threonine biosynthesis of SSW-10/SP-09. Significant changes of expression ratio to transcript levels are represented by color ( $\mathrm{p}$-value $<0.05$, and fold changes > 2.0), three independent replicate. The red colour indicates higher expression lever of SSW-10/SP-09; blue colour indicates lower expression lever of SSW-10/SP-09; gray colour indicates no changes.

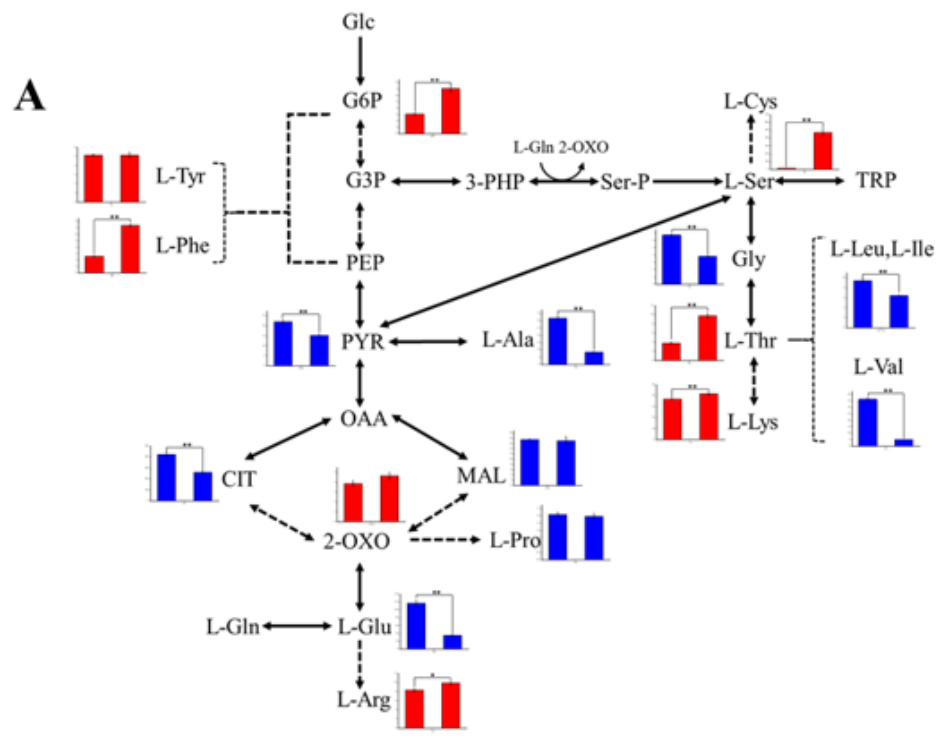

B

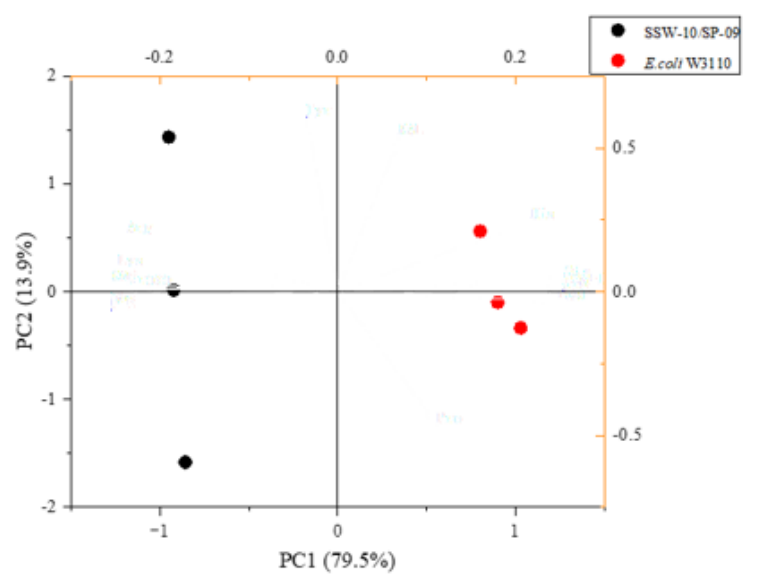

Figure 7

PCA score and intracellular metabolites of SSW-10/SP-09 and E. coli W3110. (A)17 intracellular metabolites of SSW-10/SP-09 and E. coli W3110 (three independent replicates). Significant changes in cofactors are represented by $*(p<0.05)$ and $* *(p<0.01)$. (B) PCA score.

\section{Supplementary Files}

This is a list of supplementary files associated with this preprint. Click to download.

- Additionalfile1.docx

- Additionalfile2.docx

- Additionalfile3.docx

- Additionalfile4.docx 